OPEN ACCESS

Edited by:

Inmaculada Martinez-Reyes, Max Delbrück Center for Molecular Medicine, Helmholtz Association of German Research Centers (HZ), Germany

Reviewed by: Jan Riemer,

University of Cologne, Germany John Hancock, University of the West of England, United Kingdom

${ }^{*}$ Correspondence: Erika Fernández-Vizarra Erika.Fernandez-Vizarra@ glasgow.ac.uk Kostas Tokatlidis Kostas.Tokatlidis@glasgow.ac.uk

Specialty section:

This article was submitted to

Signaling,

a section of the journal Frontiers in Cell and Developmental

Biology

Received: 04 June 2021

Accepted: 04 August 2021 Published: 07 September 2021

Citation:

Geldon S, Fernández-Vizarra E and Tokatlidis K (2021)

Redox-Mediated Regulation of Mitochondrial Biogenesis, Dynamics, and Respiratory Chain Assembly in Yeast and Human Cells. Front. Cell Dev. Biol. 9:720656. doi: 10.3389/fcell.2021.720656

\section{Redox-Mediated Regulation of Mitochondrial Biogenesis, Dynamics, and Respiratory Chain Assembly in Yeast and Human Cells}

\author{
Stefan Geldon, Erika Fernández-Vizarra* and Kostas Tokatlidis* \\ Institute of Molecular Cell and Systems Biology, College of Medical, Veterinary and Life Sciences, University of Glasgow, \\ Glasgow, United Kingdom
}

Mitochondria are double-membrane organelles that contain their own genome, the mitochondrial DNA (mtDNA), and reminiscent of its endosymbiotic origin. Mitochondria are responsible for cellular respiration via the function of the electron oxidative phosphorylation system (OXPHOS), located in the mitochondrial inner membrane and composed of the four electron transport chain (ETC) enzymes (complexes I-IV), and the ATP synthase (complex V). Even though the mtDNA encodes essential OXPHOS components, the large majority of the structural subunits and additional biogenetical factors (more than seventy proteins) are encoded in the nucleus and translated in the cytoplasm. To incorporate these proteins and the rest of the mitochondrial proteome, mitochondria have evolved varied, and sophisticated import machineries that specifically target proteins to the different compartments defined by the two membranes. The intermembrane space (IMS) contains a high number of cysteine-rich proteins, which are mostly imported via the MIA40 oxidative folding system, dependent on the reduction, and oxidation of key Cys residues. Several of these proteins are structural components or assembly factors necessary for the correct maturation and function of the ETC complexes. Interestingly, many of these proteins are involved in the metalation of the active redox centers of complex IV, the terminal oxidase of the mitochondrial ETC. Due to their function in oxygen reduction, mitochondria are the main generators of reactive oxygen species (ROS), on both sides of the inner membrane, i.e., in the matrix and the IMS. ROS generation is important due to their role as signaling molecules, but an excessive production is detrimental due to unwanted oxidation reactions that impact on the function of different types of biomolecules contained in mitochondria. Therefore, the maintenance of the redox balance in the IMS is essential for mitochondrial function. In this review, we will discuss the role that redox regulation plays in the maintenance of IMS homeostasis as well as how mitochondrial ROS generation may be a key regulatory factor for ETC biogenesis, especially for complex IV.

Keywords: mitochondria, biogenesis, protein import, redox signaling, ROS, respiratory chain assembly, MIA 


\section{INTRODUCTION}

Mitochondrial biogenesis is essential for cell fitness and viability. Mitochondria are double membrane bound organelles composed of an outer membrane (OM), intermembrane space (IMS), inner membrane (IM), and matrix that harbors its own mitochondrial genome, the mtDNA. This mtDNA encodes only 13 polypeptides in humans or 8 polypeptides in yeast cells that are translated into key components of the respiratory chain complexes embedded in the IM. Assembly of the respiratory chain complexes relies on the protein import process through which most of these subunits find their way into the organelle.

A large number of proteins imported into the intermembrane space (IMS) are cysteine rich proteins that are imported via the mitochondrial import and assembly (MIA) pathway which involves oxidation of specific cysteine residues and subsequent folding of proteins into their mature conformation thereby trapping them in this compartment. As many of the substrates of this pathway include a variety of chaperones, proteases, mitochondrial dynamics factors and assembly factors for the respiratory chain complexes, and redox regulation of the IMS plays a crucial role in a wide variety of processes within the mitochondria. In this review we give a brief overview of the protein import pathways moving on to a more detailed presentation of the redox-regulated MIA pathway with a focus on the yeast and human systems. We then discuss the redox regulation features of mitochondria dynamics and proteases in the IMS following on with an analysis of the redox regulation mechanisms that are pertinent for the assembly process of the electron transport chain (ETC) complexes. Finally, we examine the possible role of reactive oxygen species (ROS) on maintaining the homeostasis of the respiratory chain.

\section{OVERVIEW OF MITOCHONDRIAL PROTEIN IMPORT PATHWAYS}

The mitochondrial proteome consists of $1,000-1,500$ proteins (Sickmann et al., 2003; Reinders et al., 2006; Pagliarini et al., 2008; Rath et al., 2021) but only eight in the yeast S. cerevisiae and thirteen in humans, and other mammalian species, are encoded in the mitochondrial genome and translated inside the organelle. This implies that $\sim 99 \%$ of all mitochondrial proteins (1163 polypeptides in human mitochondria according to the last compendium of MitoCarta 3.0 (Rath et al., 2021) are nuclear encoded, translated on cytosolic ribosomes and guided to the mitochondria by a variety of cytosolic chaperones. From here they can be sorted within the organelle (Figure 1).

\section{Protein Entry Into Mitochondria}

The translocase of the outer membrane (TOM) complex forms the entry gate for most imported mitochondrial proteins. The TOM complex is composed of seven different functional and receptor subunits. Precursors with a cleavable N-terminal presequence are recognized on the surface of mitochondria by the Tom 20 receptor, while the Tom 70 receptor recognizes precursor proteins that lack such a presequence but contain an internal targeting signal instead (Brix et al., 1997; Yamamoto et al., 2009; Backes et al., 2018). Tom22 is the central receptor that helps recruit both Tom 20 and Tom70 to the TOM core complex and is involved in transferring preproteins from the receptor subunits to the translocation pore (Van Wilpe et al., 1999; Yamano et al., 2008). The structure of the S. cerevisiae TOM complex was recently solved using cryo-electron microscopy at a $3.8 \AA$ resolution (Araiso et al., 2019). This detailed structure revealed the architecture of the TOM entry gate providing a framework how the additional subunits Tom5, Tom6, Tom7 and Tom22 are organized within the complex. We will not provide a detailed analysis here as the TOM structural and functional features have been reviewed extensively (Shiota et al., 2015; Araiso et al., 2020).

\section{Protein Sorting in the Inner Mitochondrial Compartments}

Following translocation through the TOM complex in the OM, proteins are sorted through different import pathways into the matrix, the IM and the IMS (Jensen and Johnson, 2001; Grevel et al., 2019; Hansen and Herrmann, 2019). Most of the precursor proteins targeted to the matrix are synthesized with an $\mathrm{N}$-terminal positively charged cleavable presequence (Vögtle et al., 2009) and follow the matrix targeting pathway, which accounts for almost two thirds of all mitochondrial proteins. The presequence translocase of the inner membrane (TIM23 complex) is the key translocon that allows passage of these matrix-targeted precursor proteins through the inner membrane. The positively charged region of the presequence is recognized by the TOM receptors Tom 20 and Tom 22 that facilitate the translocation across the OM. The Tim50 subunit feeds the positively charged region into the Tim 23 channel (Dayan et al., 2019). The translocation of these precursors through the pore of the TIM23 complex is dependent on the membrane potential $(\Delta \psi)$ across the inner membrane generated from the activity of the respiratory chain complexes. Additionally, the TIM23 complex is also involved in releasing proteins, containing a strongly hydrophobic transmembrane segment adjacent to the matrix-targeting presequence, laterally into the inner membrane. These proteins start to engage with the Tim 23 channel guided by their presequence but become stalled because of their strong hydrophobic "stop-transfer" signal in the translocation pore of the Tim23 channel, preventing their complete import into the matrix. A specific cleavage of the 'stop-transfer' signal by the IMS localized IMP protease releases the mature protein into the IMS. The translocationarrest mechanism of such bipartite presequence containing preproteins requires a specific conformation of the TIM23 complex that contains Tim17, Tim21, and Tim23, termed the TIM23 ${ }^{\text {SORT }}$ translocase (Chacinska et al., 2010). By contrast, the TIM23 complex associated with the matrix-localized Pam 18 (TIM23 ${ }^{\mathrm{PAM}}$ ) blocks the lateral release into the lipid bilayer and instead promotes import into the matrix (Schendzielorz et al., 2018). Protein transport into the matrix requires the ATP-dependent activity of the mitochondrial heat shock protein 70 (mtHsp70) (Pais et al., 2011) in addition to the membrane potential. Once in the matrix, the presequence is cleaved off from 


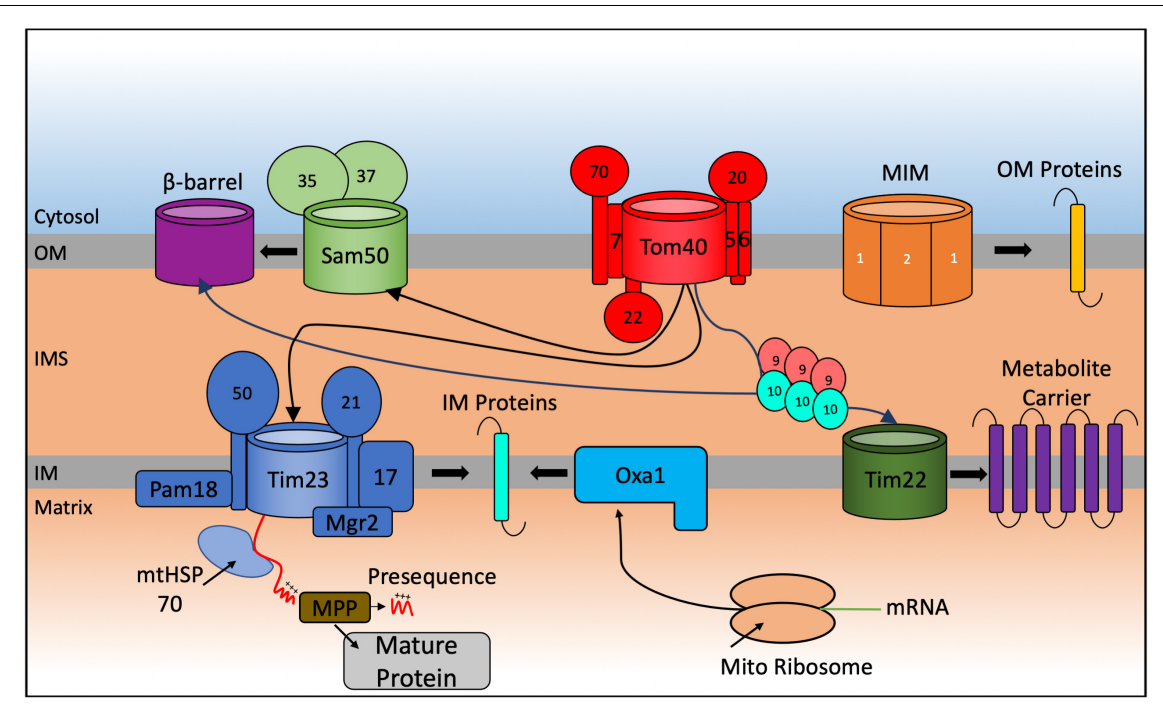

FIGURE 1 | Schematic representation of the general import pathways for proteins destined for localization to the mitochondria. Incoming nuclear-encoded proteins destined for import into the mitochondria follow a number of particular import pathways depending on the sub compartment where they become localized. Matrix targeted proteins follow the presequence pathway, passing through the TOM40, and TIM23 translocases where they become cleaved by matrix processing proteins (MPP) in the matrix to form the mature protein. Preproteins targeted to the outer membrane (OM) are inserted by the Sam complex if they are $\beta$-barrel proteins and via the mitochondrial import machinery (MIM) if they are $\alpha$-helical containing proteins. Integration of preproteins into the inner membrane (IM) involves interaction with the Tim9-Tim10 chaperone complex that targets proteins to the TIM22 translocase for membrane insertion or via a variation of the TIM23 complex that promotes integration of the protein into the IM. Mitochondrial encoded proteins are synthesized on mito ribosomes located in the matrix and inserted into the IM via the Oxa1 complex.

the precursor by the matrix processing peptidase (MPP), giving rise to the mature mitochondrial protein (Yang et al., 1991).

The mitochondrial metabolite inner membrane carrier proteins (at least 35 proteins in S. cerevisiae and more than 50 in mammalian cells) are critical for the trafficking of small metabolites and are synthesized without a cleavable presequence. They interact with the Tom70 receptor, engage with the TOM channel and are guided to the inner membrane TIM22 complex, by a number of small TIM chaperones in the IMS that escort them in the aqueous IMS preventing their aggregation. This import and insertion process constitutes the carrier pathway, and it is membrane potentialdependent but independent of ATP hydrolysis in the matrix (Sirrenberg et al., 1996).

\section{Protein Insertion Into the Mitochondrial Outer Membrane}

The mitochondrial outer membrane contains either $\beta$-barrel membrane proteins (which are absent from the inner membrane) or $\alpha$-helical transmembrane proteins. Precursors of the $\beta$-barrel proteins are first recognized by the TOM complex and then transferred to the sorting and assembly (SAM) complex from the IMS side of the OM. A recent cryo-electron microscopy structure of the SAM complex revealed that it is made up of two copies of the central subunit Sam50, forming a $\beta$-barrel channel (Takeda et al., 2021) that allows the lateral release of the precursor proteins into the outer membrane (Paschen et al., 2003; Klein et al., 2012). The SAM complex also contains the Sam35 and Sam37 proteins found on the cytosolic side of the outer membrane. Sam35 is thought to stabilize the precursor-Sam50 interaction, while Sam37 is involved in the release of substrate proteins from the SAM complex (Chan and Lithgow, 2008; Kutik et al., 2008). Transfer from the IMS to the OM is mediated by the IMS small TIM chaperones that transiently bind to exposed hydrophobic regions preventing their aggregation (Wenz et al., 2015; Weinhäupl et al., 2018). $\alpha$-helical membrane proteins in the OM follow a dedicated pathway via the mitochondrial import machinery (MIM) complex (Becker et al., 2011; Dimmer et al., 2012).

\section{Import of Proteins Into the Intermembrane Space - The MIA Pathway}

A detailed analysis of the proteome of the mitochondrial IMS for the yeast $S$. cerevisiae revealed that around 50 proteins were localized to this sub-compartment (Vögtle et al., 2012). In humans, the IMS proteome accounts for about $5 \%$ of the total mitochondrial proteome (53 proteins) (Rath et al., 2021). The majority of these IMS-located proteins lack a typical mitochondrial targeting sequence and are instead characterized by conserved cysteine residues organized into twin $\mathrm{CX}_{n} \mathrm{C}$ (typically either $\mathrm{CX}_{3} \mathrm{C}$ or $\mathrm{CX}_{9} \mathrm{C}$ ) motifs that are necessary for their import, correct folding and maturation. The oxidative folding or mitochondrial protein import and assembly (MIA) pathway relies on the function of Mia40, in yeast, and CHCHD4 (also known as MIA40), in humans, as the key protein that facilitates the disulfide bonds in these proteins (Mesecke et al., 2005; Figure 2). 


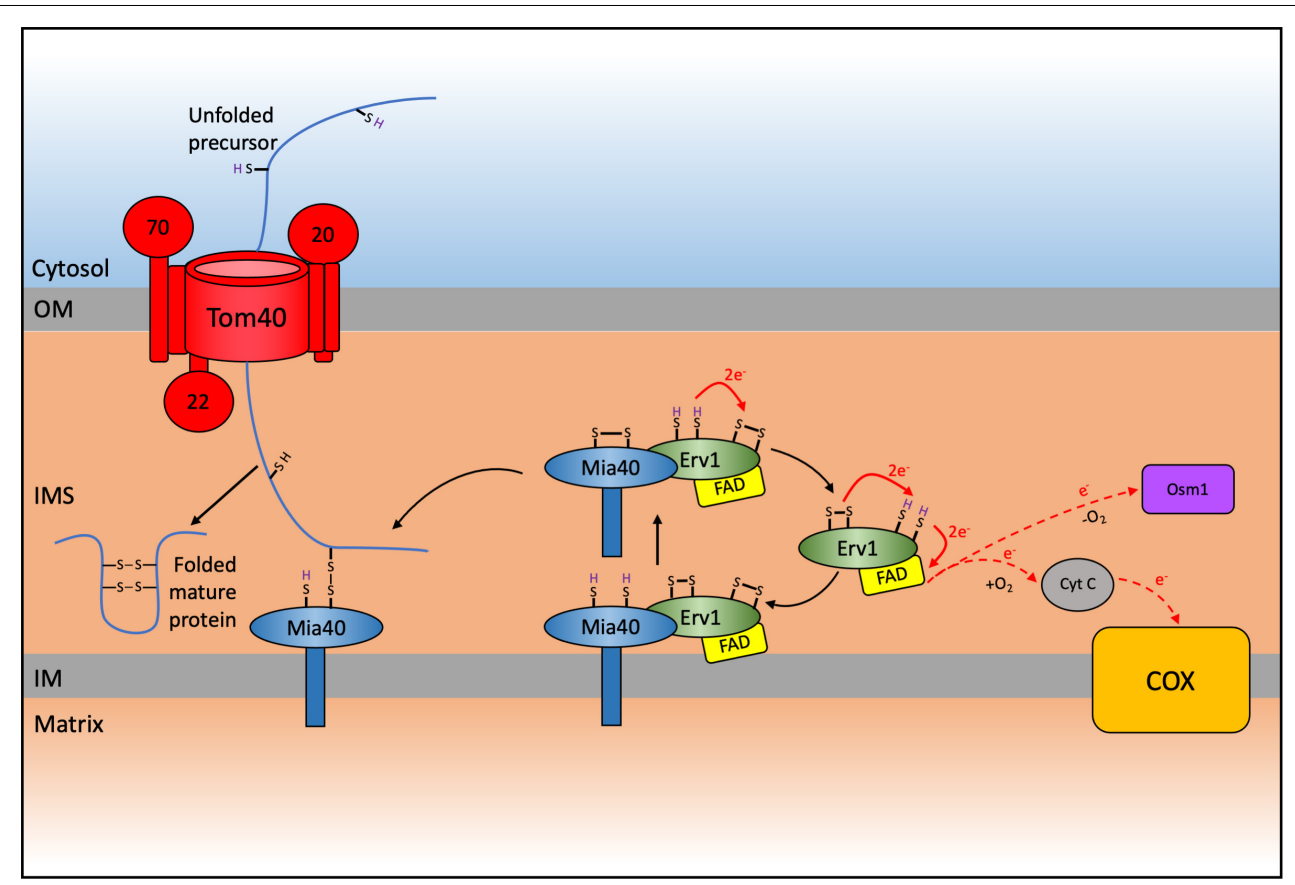

FIGURE 2 | Schematic representation of the mitochondrial import and assembly (MIA) pathway in yeast. A subset of proteins destined for the intermembrane space (IMS) are imported via the MIA pathway which results in the oxidative folding of these substrates thereby trapping them in the IMS. Nuclear encoded $\mathrm{CX}_{n} \mathrm{C}$ motif containing proteins are first imported through the TOM complex. These proteins contain an IMS-Targeting signal (ITS) that interacts with Mia40 resulting in the oxidation and subsequent folding of the substrate protein, thereby trapping it in the IMS. This interaction leaves Mia40 in a reduced state that must be reoxidized to allow it to further oxidize incoming substrates. This reoxidation is facilitated by interaction with Erv1 with subsequent electron transfer to cytochrome $c$ and complex IV (COX) of the respiratory chain in aerobic conditions, or onto Osm1 in anaerobic conditions. The system varies in humans, where CHCHD4/MIA40 is a soluble IMS protein that interacts with membrane bound AIFM1 and with ALR/GFER/ERV1 (Reinhardt et al., 2020).

Many of these classical MIA substrates are vital for the biogenesis and function of mitochondria as, for example, the members of the small Tim protein family, including Tim 8, Tim 9, Tim 10, and Tim13 (Sideris and Tokatlidis, 2007). These proteins form the Tim9-Tim10 and Tim8-Tim13 chaperone complexes that are essential to deliver hydrophobic proteins to the TIM22 complex for insertion into the inner membrane. Other examples of MIA substrates are proteins necessary for the biogenesis of the ETC complexes. These will be discussed in detail in subsequent sections and include proteins with a dual $\mathrm{CX}_{9} \mathrm{C}$ motif that are involved mostly in the assembly and maintenance of cytochrome c oxidase (COX), also known as complex IV (CIV) (Gabriel et al., 2007; Koch and Schmid, 2014a; Habich et al., 2019a; Gladyck et al., 2021). It is, however, clear that Mia40 can recognize proteins that do not have $\mathrm{CX}_{\mathrm{n}} \mathrm{C}$ motifs, like the yeast Erv1 protein (with a $\mathrm{CX}_{15} \mathrm{C}$ motif) (Terziyska et al., 2007; Kallergi et al., 2012), yeast Atp23 (with 10 cysteine residues not organized in any specific cysteine motif (Weckbecker et al., 2012), yeast Mix23 (with an unusual twin cysteine $\mathrm{CX}_{13} \mathrm{C} / \mathrm{CX}_{14} \mathrm{C}$ motif (Vögtle et al., 2012; Zöller et al., 2020), or human COA7 containing thirteen Cys residues (Mohanraj et al., 2019). Other proteins without classical $\mathrm{CX}_{\mathrm{n}} \mathrm{C}$ motifs that have been described as substrates of CHCHD4/MIA40 also include p53, AK2 and MICU1 (Zhuang et al., 2013; Petrungaro et al., 2015). It is also of note that Ccs1, the copper chaperone for $\mathrm{Cu}, \mathrm{Zn}$ superoxide dismutase (Sod1), is a Mia40 substrate in yeast but the IMS import of the human ortholog (CCS1) does not depend on CHCHD4/MIA40 (Groß et al., 2011; Suzuki et al., 2013).

The other main component of the yeast MIA pathway is the FAD-dependant sulfhydryl oxidase Erv1 (Chacinska et al., 2004; Mesecke et al., 2005). The human ortholog is known as ERV1, ALR, or GFER (Lange et al., 2001; Di Fonzo et al., 2009). Mia40 and Erv1 function as a disulfide relay system to catalyze the import of proteins into the IMS through an oxidative folding process. This results in introduction of disulfide bonds into the imported proteins, promoting their folding into their native conformation and thereby trapping them in the IMS. Substrates of the MIA pathway are translated cytosolically and pass through the TOM complex in a reduced and unfolded state (Lu et al., 2004; Sideris and Tokatlidis, 2007). During translocation these substrates interact with Mia40, which acts as a trans site receptor to drive protein import into the IMS (Milenkovic et al., 2007; Sideris and Tokatlidis, 2007; Peleh et al., 2016).

The yeast Mia40 has an $\mathrm{N}$-terminal transmembrane domain that inserts the protein to the inner mitochondrial membrane and exposes its C-terminal domain to the IMS (Chacinska et al., 2004; Naoé et al., 2004; Terziyska et al., 2005). The human MIA40 (or CHCHD4) lacks this N-terminal domain and instead is found as a soluble protein of around $15 \mathrm{kDa}$ in the mitochondrial IMS (Hofmann et al., 2005) where it interacts with the membrane anchored AIFM1 and this interaction facilitates the import of MIA40 into the IMS (Hangen et al., 2015). The 
C-terminal region was recently demonstrated to be important in maintaining the stability of the protein in the cytosol where it can often reside for extended periods as a consequence of slow import kinetics during AIFM1-mediated import (Murschall et al., 2020). However, all Mia40 homologs contain a highly conserved core domain of around $8 \mathrm{kDa}$ that harbors six conserved cysteine residues that are folded into a coiled-helixcoiled-helix (CHCH) domain (Banci et al., 2009). The structure of the human and yeast homologs was solved by NMR and X-ray crystallography, respectively (Banci et al., 2009; Kawano et al., 2009). The invariant cysteines in this domain form a redox-active $\mathrm{CPC}$ motif that can readily switch between oxidized and reduced states, followed by a twin $\mathrm{CX}_{9} \mathrm{C}$ motif that forms two structural disulfide bonds. The $\mathrm{CHCH}$ domain folds to form a characteristic hydrophobic cleft where substrates can bind and interact with Mia40 (Banci et al., 2009; Sideris et al., 2009). Most Mia40 substrates contain a hydrophobic sequence, also known as an IMS-targeting signal (ITS, Sideris et al., 2009) or alternatively termed the mitochondrial IMS-sorting signal (MISS, Milenkovic et al., 2009). This is a 9 amino acid internal peptide sequence that is necessary and sufficient for IMS targeting of proteins to Mia40. Deletion of the ITS results in a complete loss of import (Sideris et al., 2009). The sequence aids the first interaction with Mia40 via hydrophobic stacking (Milenkovic et al., 2009; Sideris et al., 2009). This initial interaction orientates the substrate toward Mia40 to allow the formation of a transient intermolecular disulfide bond between the second cysteine of the redox active CPC motif of Mia40 and the docking cysteine of the ITS in the imported substrate (Banci et al., 2009; Koch and Schmid, 2014b). This transient disulfide bond is subject to a nucleophilic attack by another cysteine in the substrate to form an intramolecular disulfide bond. This promotes the release of Mia40 and the correct folding of the protein, thereby trapping it in the IMS and completing its import process.

The introduction of a disulfide into a substrate by Mia40 leaves it in a reduced state and unable to oxidize any further imported proteins. Thus, to maintain a functional MIA pathway, Mia40 needs to continually be re-oxidized by interaction with Erv1, which contains three cysteine pairs that are highly conserved (Mesecke et al., 2005). The FAD-binding catalytic core domain has a CXXC redox-active disulfide (Cys130 - Cys133) and a C-terminal $\mathrm{CX}_{16} \mathrm{C}$ structural disulfide (Cys156 and 179). A third disulfide bond (Cys30 - Cys33) is present within the flexible $\mathrm{N}$-terminal of the protein, which is natively disordered and is involved in the interaction with reduced Mia40 and the transfer of electrons toward the redox active-site disulfide (Lionaki et al., 2010; Banci et al., 2011a, Banci et al., 2013). From here electrons are transferred to a final electron acceptor via the FAD cofactor (Banci et al., 2012). Under aerobic conditions Erv1 can either transfer electrons directly onto molecular oxygen which results in the production of hydrogen peroxide within the IMS, or onto cytochrome $c$, the mobile electron transfer protein that donates electrons to CIV (Allen et al., 2005; Dabir et al., 2007; Daithankar et al., 2009; Banci et al., 2012; Peker et al., 2021). Alternatively, under anaerobic conditions the fumarate reductase Osm 1 can be used as an electron acceptor (Neal et al., 2017).
Intriguingly, Mia40 itself is a substrate of the MIA pathway requiring interactions with endogenous Mia40 during its own import, which occurs in three steps. First, Mia40 is inserted through the Tim23 translocon in the inner mitochondrial membrane. Next, the core domain of the protein is folded through interactions with endogenous Mia40. Lastly, Mia40 interacts with Erv1 to oxidize the CPC motif to produce functional Mia40 that can oxidize incoming substrates of the MIA pathway (Chatzi et al., 2013).

\section{The Small Tim Chaperones}

The small Tim proteins that function as chaperones in the IMS were the first discovered substrates of the MIA pathway, interacting with Mia40 to control their redox-regulated import (Chacinska et al., 2004). These small Tims possess non-cleavable internal targeting signals (ITS) that harbor conserved cysteine motifs to target them to the mitochondria (Milenkovic et al., 2009; Sideris et al., 2009). The cysteines are arranged in a $\mathrm{CX}_{3} \mathrm{C}$ motif, a classical substrate motif for Mia40 (Koehler, 2004). The ITS signal directs the small Tims to the IMS where they are imported by the MIA pathway through direct interaction with Mia40 (Chacinska et al., 2004; Sideris et al., 2009). This interaction results in the oxidation of the small Tims, leading to the formation of intramolecular disulfide bonds and trapping the proteins in the IMS.

The small Tims form hexameric protein complexes consisting of either Tim9 - Tim10 or Tim8 - Tim13 with three subunits of each Tim protein. Structural analysis of the complexes revealed the subunits take on the form of an $\alpha$-propellor with two helical blades that radiate from a narrow central pore (Webb et al., 2006; Beverly et al., 2008). The subunits are stabilized by the formation of intramolecular and structural disulfide bonds. Within the IMS these complexes act as chaperones to transport incoming hydrophobic precursors across this compartment to the TIM22 complex for their insertion into the IMM. The helper of Tims 13 (Hot13p) was also shown to be involved in maintaining the small Tims in their active conformation (Curran et al., 2004).

The presence of the redox-regulated disulfide machinery in the IMS raises the question of a broader level of redox regulation in this sub-compartment that may affect not just the MIA pathway itself or import substrates for this pathway, but other important proteins and process linked to the IMS. In the next sub-sections, we will discuss in particular the redox regulation of mitochondrial dynamics and the effect of redox control on the IMS protease system. Both of these are critical for many functions of mitochondria and highlight the broader ramifications of mitochondria-specific redox control pathways.

\section{Redox Regulation of Mitochondrial Dynamics}

Mitochondria undergo coordinated processes of fission and fusion, known as mitochondrial dynamics, to regulate their size, shape, and integrity. There are several key proteins involved in the control of mitochondrial dynamics that have been demonstrated to be redox-regulated. Mitofusin proteins (Mfn1/Mfn2) are large GTPases that are implicated 
in mitochondrial fusion. This process has been shown to be triggered by oxidative stress, characterized by an accumulation of oxidized glutathione (GSSG), which in turn leads to the assembly of higher order Mfn oligomers mediated by the formation of disulfide bonds between conserved cysteine residues in the C-terminal region (Shutt et al., 2012). This region has been recently identified to be topologically located in the IMS and the conserved Cys demonstrated to be redox sensitive (Mattie et al., 2018). Redox regulation in this compartment mediates the formation of disulfide bonds in the Mfn proteins thereby driving oligomerization and triggering mitochondrial fusion. Therefore, the redox state of the IMS is likely to play a role in controlling mitochondrial dynamics.

ROS modulator 1 (ROMO1) was identified as a key regulator of mitochondrial fusion, with knockout cells displaying increased fragmented mitochondrial networks. ROMO1 is also involved in the generation of ROS by complex III (CIII) of the ETC and can form disulfide bridges to become incorporated into inactive highmolecular weight complexes (Chung et al., 2006; Norton et al., 2014). Disulfide formation occurs between the Cys15 and Cys79 residues in response to oxidative stress, inhibiting fusion and maintaining a fragmented mitochondrial network (Norton et al., 2014). More recently ROMO1 was found to be required for the import of the human inner membrane YME1L protease (Richter et al., 2019).

During mitochondrial fusion there is separate merging of the outer and inner mitochondrial membranes. Fusion of inner mitochondrial membranes involves heterotypic interactions between the dynamin-like GTPase optic atrophy 1 (OPA1) and cardiolipin (Ban et al., 2017; Liu and Chan, 2017). Mammalian OPA1 is an inner membrane associated protein that exists in either a long form (L-OPA1) or soluble short-form (S-OPA1) conformation (Del Dotto et al., 2018). Conversion of OPA1 between these two isoforms occurs as a result of proteolytic cleavage of L-OPA1 that is catalyzed by the OMA1 and YME1L proteases (Anand et al., 2014). A balance of both the longand short- isoforms of OPA1 depends on these proteases and is required to maintain normal mitochondrial morphology.

\section{Redox Regulation of Proteases in the IMS}

YME1L, the human ortholog of yeast Yme1, is an integral membrane protein with its C-terminal domain exposed to the intermembrane (Stiburek et al., 2012). Yme1 is a subunit of the inner membrane anchored oligomeric complex known as the i-AAA protease that displays both ATP-dependent proteolytic and chaperone-like activities in the IMS (Leonhard et al., 1996, 1999; Schreiner et al., 2012). Yme1 is involved in the degradation of misfolded inner membrane proteins and more recently shown to be implicated in the clearance of the small Tim9 and Tim10 IMS chaperones (Leonhard et al., 2000; Baker et al., 2012). YME1L is rapidly degraded by OMA1, an ATP-independent protease, upon oxidative stress conditions (Rainbolt et al., 2015). This suggests that YME1L is a stress-sensitive protease and thus degradation of YME1L under oxidative stress conditions may provide a mechanism to segregate damaged mitochondria from the healthy pool, by restricting the ability of YME1L to regulate the fusion activity of OPA1 through its degradation. More recently it was demonstrated that YME1L adopts unique conformations depending on the ATP and ROS concentrations (Brambley et al., 2019). Under oxidative stress conditions, YME1L undergoes a conformational change, exposing OMA1 recognition sites that were previously unreachable in basal conditions, further supporting the mechanism of YME1L degradation by OMA1 during oxidative stress (Brambley et al., 2019).

Oma1, responsible for mediating OPA1 degradation, is an IMS facing ATP-independent metalloprotease embedded in the inner mitochondrial membrane displaying enhanced activity in response to stress conditions (Käser et al., 2003; Head et al., 2009). Omal is synthesized as a pre-pro-protein of $60 \mathrm{kDa}$ that upon import into the mitochondria is proteolytically processed to a mature $40 \mathrm{kDa}$ form (Head et al., 2009). The protein is normally dormant under normal physiological conditions but becomes rapidly activated upon changes in membrane potential, chronic hyperpolarization and oxidative stress (Bohovych et al., 2014). The $40 \mathrm{kDa}$ Omal is proposed to be a stress-sensitive pro-protein that undergoes further autocatalytic cleavage in response to stress insults to produce the active form of the protein that is involved in proteolysis of substrates (Baker et al., 2014).

Omal exists in a semi-oxidative state in both yeast and mammalian cell types and the activity and stability of the homooligomeric complex was found to be altered in a redox sensitive manner. Two evolutionary conserved cysteine residues, Cys272 and Cys332, which are exposed to the IMS can form a disulfide bond that likely influences the stability of the oligomeric complex. It is proposed that the formation of this disulfide is controlled by the redox status of the cysteine residues which act as a redox sensor to influence the proteolytic activity of Omal in response to deviations from normal cell homeostasis (Bohovych et al., 2019).

A subset of IMS-located proteases has been shown to be involved in the proteolytic control of ETC assembly and stability, including the m-AAA, i-AAA and Oma1. These enzymes control the proteolysis of unassembled, misfolded OXPHOS subunits to prevent the formation of dysfunctional ETC subunits (Bohovych et al., 2015). Omal in particular is involved in the degradation of non-hemylated cytochrome $c$ oxidase subunit 1 (Cox1) (Bestwick et al., 2010b; Khalimonchuk et al., 2012). In human mitochondria, the proteolytic activity of YME1L was shown to be involved in preventing the accumulation of nonassembled respiratory chain subunits including COX4, MT-ND1 and NDUFB6 (Stiburek et al., 2012).

In $S$. Cerevisiae, Atp23 was identified as an IMS protease required for the processing of the mtDNA-encoded subunit 6 of the mitochondrial ATPase (Atp6) (Osman et al., 2007). Atp23 contains ten cysteine residues, that during the import and folding into mitochondria form five disulfide bonds. The reduced Atp23 precursor is translocated into the IMS where Mia40 is then involved in introducing the disulfide bonds to promote folding of Atp23 into its mature conformation (Weckbecker et al., 2012).

The morphology of the inner membrane is regulated by the mitochondrial contact site and cristae organization system (MICOS) complex (Harner et al., 2011). Mic19, a peripheral 
inner membrane component of this complex is involved in the maintenance of the architechture of the inner membrane. Human MIC19 has five cysteine residues, four of which are arranged in a twin $\mathrm{CX}_{9} \mathrm{C}$ motif in the coiled-coil helix coiled-coil helix fomain, a typical motif for Mia40 substrates. This domain was shown to be essential for import of MIC19 into mitochondria and MIC19 demonstrated to form a transient disulfide-bond intermediate involving its Cys193 residue (Darshi et al., 2011, Darshi et al., 2012). Yeast Mic19, however, lacks the typical $\mathrm{CX}_{9} \mathrm{C}$ motif, and instead contains two conserved cys residues in a $\mathrm{CX}_{10} \mathrm{C}$ motif. Yeast Mic19 was identified in two different redox states in the mitochondria. The oxidized form displays an intermolecular disulfide with Mic60, which is not essential for its integration into the complex, but does play a role in the stability of the MICOS complex (Sakowska et al., 2015). This suggests that Mic19 may be a redox-sensor regulator of MICOS function and, therefore, of maintenance of inner membrane morphology.

\section{REDOX-REGULATION OF OXPHOS COMPONENTS AND BIOGENESIS FACTORS}

Many of the import, dynamics and redox-regulated processes mentioned so far culminate in the biogenesis of the oxidative phosphorylation (OXPHOS) system. This is physically located in the mitochondrial inner membrane (therefore in contact to the IMS on the one side) and it is composed of the four complexes (complexes I-IV) of the respiratory or ETC, which transfer reducing equivalents from $\mathrm{NADH}$ or $\mathrm{FADH}_{2}$ to oxygen, reducing it to water, using the two mobile electron carriers: coenzyme Q (CoQ) and cytochrome $c$. Electron transfer through complexes I, III and IV is coupled with proton pumping from the matrix to the IMS. This electrochemical gradient generates the protonmotive force ( $\mathrm{pmf}$ ) employed by the ATP synthase (or complex V) for the synthesis of the majority of the cellular ATP in aerobic eukaryotes (Wikström et al., 2015). Complexes I, III, IV, and V are large multimeric enzymes whose structures span the IMM, with subunits that protrude either in the matrix, the IMS or both (Letts and Sazanov, 2017). The processes of assembly and maturation of these complexes are intricate and require the action of a significant number of proteins, generically called assembly factors, that are not part of the mature complex but are necessary for ETC biogenesis. The structure and assembly of the respiratory complexes seem to be conserved for the most part between yeast and humans, except for the absence of a multimeric, and proton pumping complex I in $S$. cerevisiae (Signes and FernandezVizarra, 2018). There is an additional level of complexity in the organization of the ETC, which is the formation of supercomplex structures. In yeast, all of CIV is associated with the invariantly dimeric CIII $\left(\mathrm{CIII}_{2}\right)$ in $\mathrm{III}_{2} \mathrm{IV}_{1-2}$ stoichiometries (Hartley et al., 2019; Rathore et al., 2019). In mammalian mitochondria, CI, $\mathrm{CIII}_{2}$ and $\mathrm{CIV}$ associate with different stoichiometries into supercomplexes, in which $\mathrm{CIII}_{2}$ is always present, that coexist with the individual non-associated complexes (Letts and Sazanov, 2017; Lobo-Jarne and Ugalde, 2018).
Several structural subunits and assembly factors directly involved in OXPHOS biogenesis are Cys-containing proteins located in the IMS and, therefore, potentially subject to redox regulation (Habich et al., 2019b; Reinhardt et al., 2020). In addition, many of these are MIA40/CHCHD4 substrates (Table 1).

The Cys residues in these proteins are important for their biogenesis (i.e., their import and stability in the IMS), but in some cases also for their function (Gladyck et al., 2021). Most members of this group of proteins are also interesting from a medical point of view, as pathological variants in several genes encoding them have been found associated with respiratory chain deficiency and mitochondrial disease (Fernandez-Vizarra and Zeviani, 2021). Interestingly, the majority of IMS-located assembly factors appear to be involved in the maturation of CIV (Khalimonchuk and Winge, 2008; Longen et al., 2009; Bourens et al., 2013; Timón-Gómez et al., 2018; Gladyck et al., 2021). In addition to these, COA8 is a particular case of a CIV assembly factor, located in the IM facing the matrix, containing Cys residues within and immediately after its MTS and whose import and/or stability appears to be redox regulated (Signes et al., 2019).

\section{Role of IMS Proteins in Complex I Biogenesis}

The MIA pathway has been thoroughly studied using the yeast S. cerevisiae as a reference model (Chatzi and Tokatlidis, 2013). However, there is no multimeric complex I (CI) present in this unicellular organism, having instead three monomeric NADH dehydrogenases denominated Ndi1, Nde1, and Nde2 (Velázquez and Pardo, 2001). Nonetheless, the strong dependence of the mammalian CI biogenesis on the MIA pathway was made evident by the fact that Apoptosis Inducing Factor Mitochondria Associated 1 (AIFM1) deficiency, which was discovered to be an important interactor of CHCHD4 in the IMS (Hangen et al., 2015). AIFM1 was originally discovered as a caspaseindependent effector of cell death when migrating from the mitochondrion to the nucleus (Susin et al., 1999). However, it soon became clear that AIFM1 defects were related with a strong mitochondrial CI deficiency (Vahsen et al., 2004; Bénit et al., 2008). Subsequent studies revealed that loss of AIFM1 function produced a more generalized combined respiratory chain deficiency in mouse and human cells (Ghezzi et al., 2010; Delavallée et al., 2020), but the full ramifications of the AIFM1CHCHD4 interaction remain to be resolved (Reinhardt et al., 2020). More recently and using Drosophila melanogaster models, it was suggested that the dependency of CI biogenesis on AIFM1 was not direct but a consequence of decreased Mic19 levels instead (Murari et al., 2020).

More specifically, four CI supernumerary subunits, i.e., outside the fourteen evolutionarily conserved core subunits, are located in the IMS (Zhu et al., 2016). These are NDUFA8, NDUFB7, NDUFS5 and NDUFB10 (Table 1 and Figure 3), the first three subunits are CHCHD4 substrates containing typical twin $\mathrm{Cx}_{9} \mathrm{C}$ motifs (Szklarczyk D. et al., 2011; Fischer et al., 2013). NDUFB10 is also imported into the IMS via CHCHD4 (Friederich et al., 2017), although it appears to contain two extra 
TABLE 1 | IMS-located Cys-rich structural subunits of the ETC complexes and assembly factors.

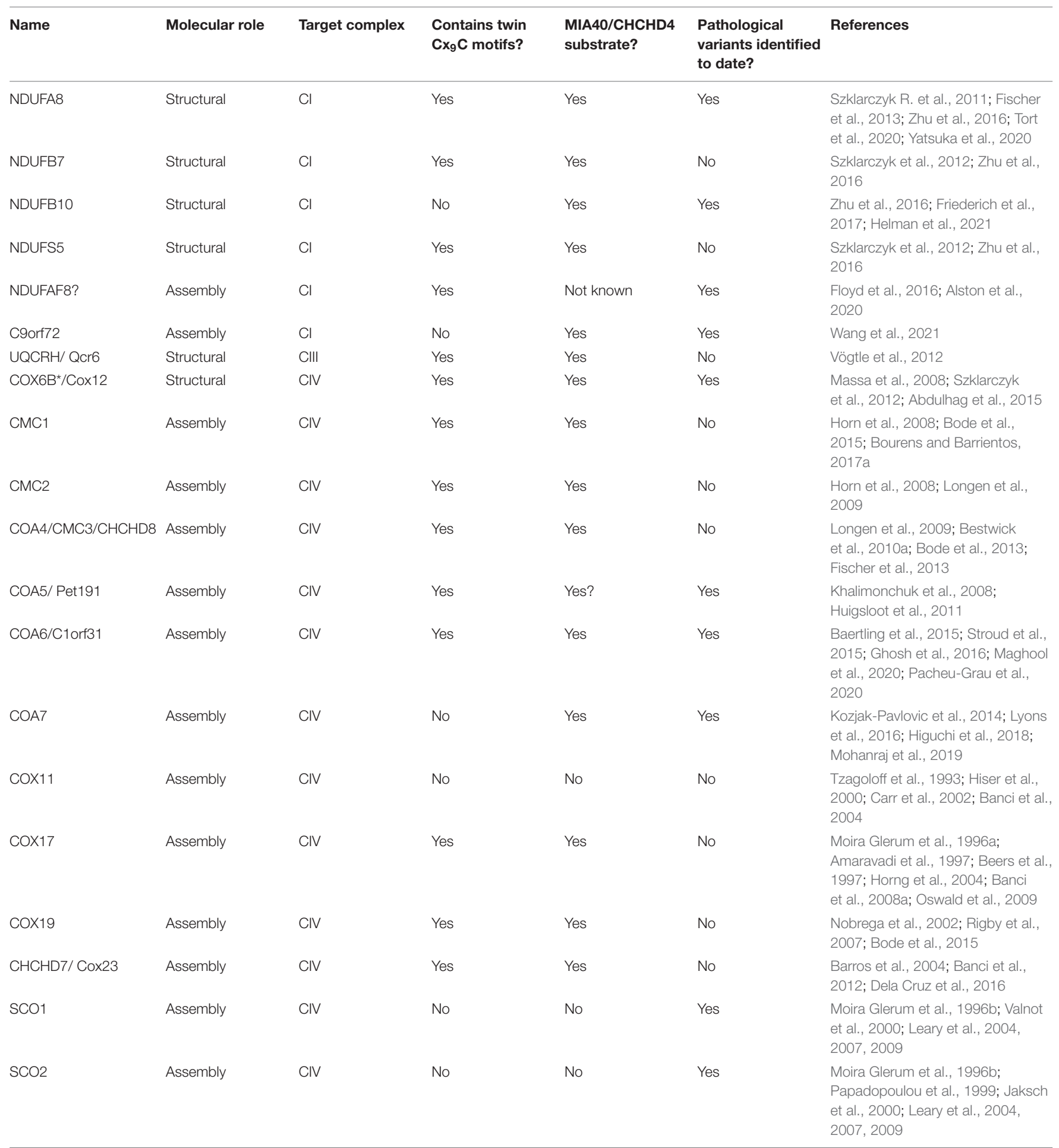

${ }^{*}$ Two isoforms of COX6B exist: the ubiquitously expressed COX6B1 and the testis specific COX6B2 (Sinkler et al., 2017).

disulfide bonds, all of which most probably contribute to the stability of the complex (Zhu et al., 2016). In fact, lack of any of these four subunits is detrimental to the assembly of CI (Stroud et al., 2016). In accordance, a pathological variant in a conserved Cys residue in NDUFB10 and those in NDUFA8 predicting changes in conserved Arg residues located at the vicinity of the $\mathrm{CX}_{9} \mathrm{C}$ motifs result in the structural loss of CI (Friederich et al., 2017; Tort et al., 2020; Yatsuka et al., 2020), reinforcing the importance of these domains for the import and/or stability of these IMS subunits and, consequently, that of the whole complex. 


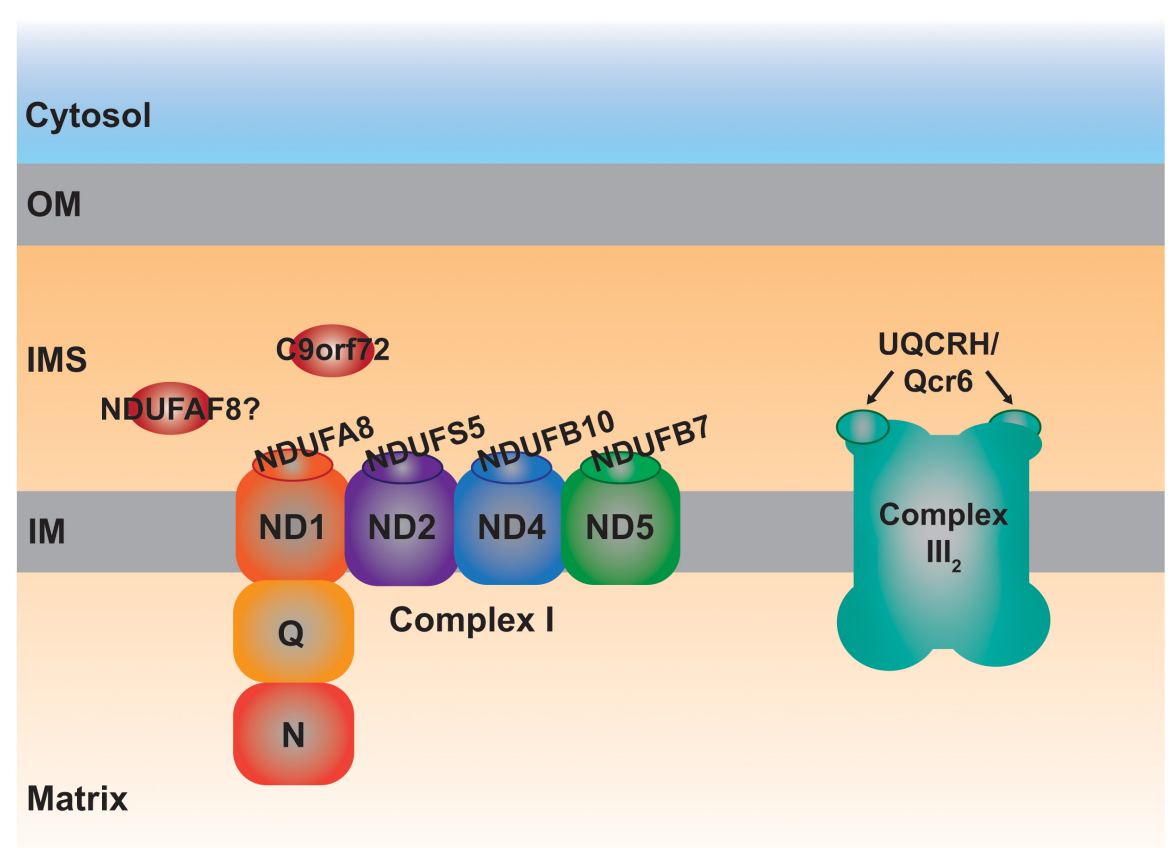

FIGURE 3 | Schematic representation of the MIA40 protein substrates located in the IMS involved in the assembly of complexes I and III 2 . Each one of the IMS Cl structural subunits, NDUFA8, NDUFS5, NDUFB10, and NDUFB7 belongs to a different module (ND1, ND2, ND4, and ND5, respectively) of the membrane arm, responsible for proton pumping. The peripheral arm of $\mathrm{Cl}$ is composed of the quinone binding $(\mathrm{Q})$ and $\mathrm{NADH}$ dehydrogenase $(\mathrm{N})$ functional modules. UQCRH, Qcr6 in yeast, is an IMS-located supernumerary subunit.

NDUFAF8 is a CI assembly factor that was identified through proteomic studies as an interactor of other CI-related proteins and then determined to be encoded by a mitochondrial disease gene (Floyd et al., 2016; Alston et al., 2020). Sequence analysis predicted its IMS localization due to the presence of twin $\mathrm{CX}_{9} \mathrm{C}$ motifs. However, even though the exact submitochondrial localization has not been proven experimentally, it is likely that NDUFAF8 is located in the matrix due to its strong interaction with NDUFAF5, a well-known matrix protein (Floyd et al., 2016; Alston et al., 2020).

Defects in C9orf72 have been associated with the development of amyotrophic lateral sclerosis and frontotemporal dementia (ALS/FTD) but the molecular functions of this protein are still unclear (Braems et al., 2020). Very recently it was determined that a proportion of $\mathrm{C} 9 \mathrm{orf} 72$ is imported into the mitochondrial IMS via AIFM1/CHCHD4 where it binds to the prohibitin complex and the m-AAA protease (Merkwirth and Langer, 2009) regulating the proteolysis of the CI assembly factor TIMMDC1 (Guarani et al., 2014) and, consequently, the amounts of fully assembled CI (Wang et al., 2021).

\section{Role of IMS Proteins in Complex III Biogenesis}

Qcr6 in yeast and UQCRH in mammals, is the only structural component of the ten subunits that constitute the cytochrome $b c_{1}$ complex (or complex III; $\mathrm{CIII}_{2}$ ) localized completely in the IMS and containing $\mathrm{Cx}_{9} \mathrm{C}$ motifs (Iwata et al., 1998; Hunte et al., 2000; Szklarczyk R. et al., 2011; Vögtle et al., 2012). Qcr6/UQCRH is a supernumerary subunit, not involved in the catalytic Q-cycle, whose function is still unclear. The first observations in $\Delta$ qcr6 strains showed normal growth in non-fermentable carbon sources and $\mathrm{CIII}_{2}$ activity. However, further investigations revealed a temperature-sensitive petite phenotype associated with a defect in the assembly of the $b c_{1}$ complex and lack of maturation of cytochrome $c_{1}$ (Cyt1), one of the three catalytical subunits (Yang and Trumpowers, 1994). Using different deletion strains, including that of Qcr6, it was determined that the subunit was incorporated on its own in the middle states of the assembly pathway (Zara et al., 2009). However, proteomic studies using a human cell line with a strong defect in $\mathrm{CIII}_{2}$ assembly, revealed the formation of intermediates containing UQCR10, cytochrome $c_{1}$ (CYC1) and most probably UQCRH as well (Protasoni et al., 2020). One can speculate that Qcr6/UQCRH would somehow contribute to the maturation of $\mathrm{CYC} 1$ before it is incorporated into nascent $\mathrm{CIII}_{2}$ also in human mitochondria. This possible function and the involvement of a redox regulatory mechanism through the Cys residues present in UQCRH, remains an interesting aspect to investigate.

\section{Role of IMS Proteins in Complex IV Biogenesis}

Of all the ETC complexes, cytochrome c oxidase (COX) or complex IV (CIV) is probably the most heavily dependent on Cys-rich redox regulated IMS proteins for its biogenesis and function. COX catalysis, oxidizing cytochrome $c$, and reducing molecular oxygen, involves the presence of two heme $a$ moieties 
and one copper $\left(\mathrm{Cu}_{\mathrm{B}}\right.$ center) ion in $\mathrm{Cox} 1 / \mathrm{MT}-\mathrm{CO} 1$, and two $\mathrm{Cu}$ ions ( $\mathrm{Cu}_{\mathrm{A}}$ center) in Cox2/MT-CO2 (Wikström et al., 2018). The processes of metal cofactor insertion, i.e. hemylation and $\mathrm{Cu}$ delivery, occur in the IMS and therefore, a significant number of Cys-rich proteins located in this compartment seem to be involved in these processes, especially in the formation of the $\mathrm{Cu}_{\mathrm{A}}$ site, as well as in the stabilization of these two COX subunits in early assembly stages (Khalimonchuk and Winge, 2008; Jett and Leary, 2018; Timón-Gómez et al., 2018; Gladyck et al., 2021; Table 1 and Figure 4). In addition to all the assembly factors that will be described below, there is one structural subunit exclusively localized in the IMS, which is yeast Cox12 or human COX6B1 (ubiquitous isoform) or COX6B2 (testis-specific isoform), containing one $\mathrm{CX}_{9} \mathrm{C}$ and one $\mathrm{CX}_{10} \mathrm{C}$ motif (Tsukihara et al., 1996). The first mammalian CIV structure was in dimeric form, appearing COX6B1 to serve as a bridge and stabilize the COX dimer, as well as modulating the interaction with cytochrome $c$ (Kadenbach and Hüttemann, 2015). However, it was recently determined that the monomer harboring COX6B1, could also be isolated and that it displayed high activity (Shinzawa-Itoh et al., 2019). Apart from a stabilization role, a function in $\mathrm{Cu}$ delivery to the active center of Cox2/MT-CO2 was also proposed for Cox12/COX6B1 (Ghosh et al., 2016). In any case, this structural subunit is clearly important for completion of the assembly process and for the activity of the enzyme, as mutations destabilizing COX6B1 or Cox12 result in assembly defects and COX deficiency in human and yeast (Massa et al., 2008; Abdulhag et al., 2015).

Cmcl was firstly identified in yeast as an IMS-located protein containing twin $\mathrm{CX}_{9} \mathrm{C}$ motifs and imported by the MIA pathway that was necessary for COX expression (Horn et al., 2008; Bourens et al., 2012; Fischer et al., 2013). Later, it was determined that human CMC1 was necessary for the stabilization of MT-CO1, being released from the first intermediate of the MT-CO1 module once this subunit joins the early nuclearencoded subunits COX4 and COX5A (Bourens and Barrientos, 2017a). The exact function of CMC1 is still not clear but it was proposed to either bind $\mathrm{Cu}$ itself or to somehow assist the process of MT-CO1 metalation (Horn et al., 2008; Bourens and Barrientos, 2017a).

Cmc2 was identified in yeast via a screening of all the genes encoding for $\underline{\mathrm{CX}}_{9} \mathrm{C}$ motif-containing proteins (Longen et al., 2009). Deletion of Cmc2 produced a respiratory-deficient phenotype associated with low COX activity (Longen et al., 2009; Horn et al., 2010). Cmc2 is homologous to and interacts with $\mathrm{Cmcl}$, cooperating in COX assembly with a different nonoverlapping molecular role. The human and C. elegans CMC2 orthologs contain the conserved Cys residues, are localized in mitochondria and appear to be involved in CIV biogenesis as well (Horn et al., 2010).

Cmc3 is another member the group of $\mathrm{Cx}_{9} \mathrm{C}$ proteins identified in yeast, also related with COX biogenesis (Longen et al., 2009). This protein was later renamed Coa4 (cytochrome c oxidase assembly number 4) and its involvement in CIV assembly was confirmed being identified as a genetic suppressor of mutations in Shy1 modeling those found in the human ortholog SURF1 and associated with Leigh syndrome (Petruzzella et al., 1998; Zhu et al., 1998; Bestwick et al., 2010b). The twin $\mathrm{CX}_{9} \mathrm{C}$ motives in Coa4/Cmc3 are highly conserved in the human protein, which is known also as CHCHD8, being also imported

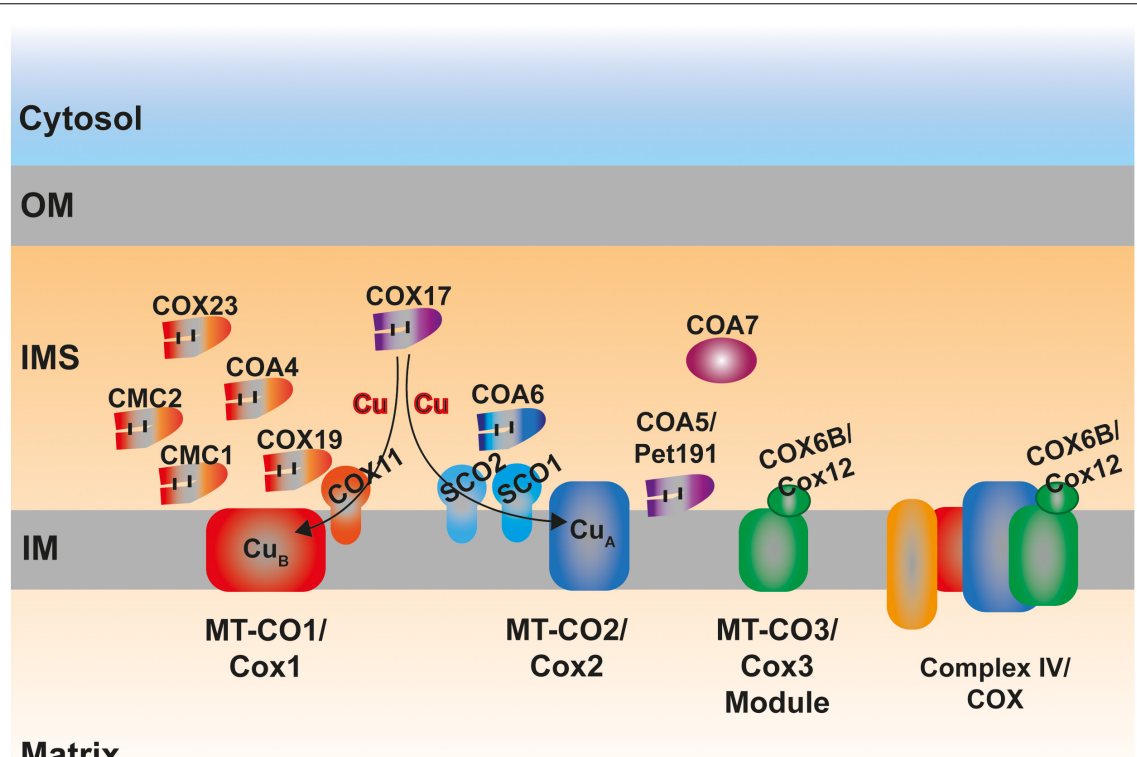

FIGURE 4 | Schematic representation of the MIA40 protein substrates located in the IMS involved in the assembly of complex IV (COX). The proteins involved in the stabilization and metalation of MT-CO1 and MT-CO2 are indicated in red and blue color, respectively. COX17 is the archetypal twin CX ${ }_{9} \mathrm{C}$ protein, mediating copper (Cu) delivery to the active centers of both MT-CO1 and MT-CO2. The exact molecular role of COA5/Pet191 and COA7 is still unknown. COX6B, Cox12 in yeast, is the only COX subunit fully localized in the IMS. 
into the IMS using the oxidative folding pathway (Fischer et al., 2013), although its direct relationship with human CIV biogenesis has not been proven experimentally yet.

Pet191 was also determined to be important for COX activity in a screen for respiration deficient yeast strains (McEwen et al., 1993). It contains a variation of the twin $\mathrm{Cx}_{9} \mathrm{C}$ motifs (i.e., two $\mathrm{Cx}_{9} \mathrm{C}$ and one $\mathrm{Cx}_{10} \mathrm{C}$ ) and there are still conflicting evidences to whether its import in the IMS is mediated by Mia40 and Erv1 or not (Khalimonchuk and Winge, 2008; Bragoszewski et al., 2013). Although its involvement in COX biogenesis was clearly proven, Pet191 is not a Cu-binding protein (Khalimonchuk and Winge, 2008). C2orf64, also known as COA5, is the human ortholog of S. cerevisiae Pet191 (Szklarczyk et al., 2012). A pathological variant in C2orf64 was associated with COX activity and assembly defects. Although the exact molecular role of this protein remains unknown, its levels are increased in cells where the MT-CO2 copper chaperones $\mathrm{SCO} 1$ and $\mathrm{SCO} 2$ are defective (Leary et al., 2013). In addition, the pattern of CIV subassemblies accumulated in the patient-derived cultured cells indicated a function in the early steps of assembly (Huigsloot et al., 2011).

Coa6 in yeast is a COX assembly factor as well as an IMSlocalized protein and a substrate of the MIA import pathway (Vögtle et al., 2012). The human and zebrafish orthologs also contain the conserved $\mathrm{CX}_{9} \mathrm{CX}_{\mathrm{n}} \mathrm{CX}_{10} \mathrm{C}$ motifs and have been proven to be important for the correct biogenesis of CIV (Szklarczyk et al., 2012; Ghosh et al., 2014; Baertling et al., 2015; Pacheu-Grau et al., 2015; Stroud et al., 2015). The fact that $\mathrm{Cu}$ supplementation restored the growth of defective strains in fermentative substrates, the fact that $\mathrm{COA} 6$ binds $\mathrm{Cu}$ in vitro, together with the connection of the protein with SCO1 and SCO2 and with MT-CO2 maturation, led to the idea that COA6 was a Cu-binding protein involved in the process of delivery of this metal to the $\mathrm{Cu}_{\mathrm{A}}$ site (Ghosh et al., 2014, 2016; Baertling et al., 2015; Pacheu-Grau et al., 2015; Stroud et al., 2015; Bourens and Barrientos, 2017b; Aich et al., 2018). However, more recent studies have suggested that COA6 is a thiol-reductase binding SCO1 and/or SCO2 and catalyzing the reduction of critical Cys residues in SCO1 and/or SCO2 as well as MT-CO2 allowing the transfer and binding of $\mathrm{Cu}$ to MT-CO2 (Soma et al., 2019; Pacheu-Grau et al., 2020). The exact COA6 binding partners and mechanisms are still not completely clear as the interpretation of the results varied in different laboratories depending on the experimental approach used (Maghool et al., 2020).

COA7/C1orf63/SELRC1 is a protein only present in metazoa that was originally studied as a Mitofilin interactor whose decreased levels were associated with defects in the respiratory chain (Kozjak-Pavlovic et al., 2014). Although one report localized this protein within the mitochondrial matrix (Lyons et al., 2016), more detailed biochemical analyses determined its IMS localization (Kozjak-Pavlovic et al., 2014; Mohanraj et al., 2019). Although it does not contain the typical $\mathrm{Cx}_{3} \mathrm{C}$ or $\mathrm{Cx}_{9} \mathrm{C}$ motifs, it is a Cys-rich protein that it is imported inside the mitochondria via CHCHD4 (Mohanraj et al., 2019). The first indication that COA7 is involved in COX biogenesis came from the fact that pathological variants in the COA7 gene are associated with mitochondrial CIV deficiency in humans
(Lyons et al., 2016; Higuchi et al., 2018; Ban et al., 2021). Recent data suggest that it is a haem-binding protein involved in the early stages of COX assembly (Formosa et al., 2021). The right Cys composition in COA7 was shown to be crucial for IMS import efficiency and for its stability (Mohanraj et al., 2019).

Cox11 deficiency in yeast results in decreased COX levels (Tzagoloff et al., 1990). Originally proposed to be involved in heme $a$ synthesis (Tzagoloff et al., 1993) it is clear now that it is a $\mathrm{Cu}$ binding protein involved in the formation of the $\mathrm{Cu}_{\mathrm{B}}$ center in Cox1, through conserved Cys residues in its Cu-binding motif (Hiser et al., 2000; Carr et al., 2002; Banci et al., 2004). A gene encoding a protein showing high homology to yeast Cox11 is present in the human genome (Petruzzella et al., 1998) and although the direct involvement of COX11 in metalation human CIV assembly has not yet been proven, it was shown to interact with CIV subunits and assembly factors (Vidoni et al., 2017).

Cox17 is the archetypal twin $\mathrm{CX}_{9} \mathrm{C}$ IMS protein involved in $\mathrm{Cu}$ binding in mitochondria, and it has been extensively studied at the functional and structural levels both in yeast and human systems (Gladyck et al., 2021). Cox17 plays a fundamental role in $\mathrm{COX}$ biogenesis by donating $\mathrm{Cu}$ to Scol for metalation of Cox 2 on one side, and to Cox 11 for the formation of the $\mathrm{Cu}_{\mathrm{B}}$ center, on the other (Horng et al., 2004; Cobine et al., 2006, 2021). The highly conserved residues contained in the $\mathrm{Cx}_{9} \mathrm{C}$ motifs and in the $\mathrm{Cu}$ binding motif are necessary for import using the MIA system, binding of $\mathrm{Cu}$, oligomerization and promoting CIV assembly (Heaton et al., 2000, 2001; Palumaa et al., 2004; Mesecke et al., 2005; Banci et al., 2008a,b, 2011b). Although Cox17 is found both in the IMS and the cytosol and for that reason it was proposed to act as a $\mathrm{Cu}$ shuttle to the inside of mitochondria (Beers et al., 1997), other investigations point out to the fact that the only active partially oxidized form of Cox17 is the one present in the IMS (Maxfield et al., 2004; Palumaa et al., 2004; Banci et al., 2008b). COX17 is also an essential protein in mammals as knocking-out the mouse gene leads to embryonic lethality (Takahashi et al., 2002). Human cell lines with knock-down expression of COX17 display decreased amounts of MT-CO1 and MT-CO2 together with the accumulation of assembly intermediates containing MT-CO1 but lacking MT-CO2 (Oswald et al., 2009; Vanišová et al., 2019). Curiously, the proportion of CIV associated with complexes I and III within the supercomplexes was more sensitive to the loss of COX17 that the "free" complex (Oswald et al., 2009). In addition, intramitochondrial $\mathrm{Cu}$ amounts were reduced in human cells where COX17 expression was stably knocked down (Vanišová et al., 2019). All in all, these observations point out to a completely conserved function of COX17 between yeast and humans.

The amino acid sequence of Cox19 is homologous to that of Cox17, containing the twin $\mathrm{CX}_{9} \mathrm{C}$ motifs but lacking the additional $\mathrm{Cys}$ residues of the $\mathrm{Cu}$ binding domain (Gladyck et al., 2021). As indicated by its name it is also a necessary factor for COX biogenesis (Nobrega et al., 2002). Similarly, the yeast and human proteins also localize both in the cytosol and mitochondria, being the steady-state levels and distribution of COX19 Cu-dependent (Nobrega et al., 2002; Leary et al., 2013). The import into the IMS is mediated by Mia40/CHCHD4 
(Fischer et al., 2013) and Cox19 also shows $\mathrm{Cu}$ binding properties in vitro (Rigby et al., 2007), whereas, in vivo $\mathrm{Cu}$ binding by Cox19 appears to be less likely. COX19 interacts with COX11 in a redox regulated manner, most likely to keep the $\mathrm{Cu}$-binding Cys residues of COX11 reduced and, therefore, in an active form (Bode et al., 2015; Cobine et al., 2021).

Cox23 was again identified in $S$. cerevisiae as a protein necessary for COX biogenesis showing high homology to Cox17 (Barros et al., 2004) with a potential function in Cox1 maturation (Dela Cruz et al., 2016). Structural analysis of the human homolog $\mathrm{CHCHD} / \mathrm{COX} 23$, predicted the presence of an ITS and the dependence on MIA40 for its folding creating the typical disulfide bridges between the twin $\mathrm{CX}_{9} \mathrm{C}$ motifs (Banci et al., 2012). Interestingly, the levels of human COX23 decrease when the $\mathrm{Cu}$ binding proteins $\mathrm{SCO} 1$ and $\mathrm{SCO} 2$ are defective or in the presence of a Cu chelating agent (Leary et al., 2013).

SCO1 and SCO2 are not members of the CHCHD family, but they are IM tethered proteins facing the IMS containing Cys residues important for $\mathrm{Cu}$ binding, essential for their function in the metalation of MT-CO2 (Nittis et al., 2001; Leary et al., 2004). As pointed out above, there is clearly an interplay between SCO1 and $\mathrm{SCO} 2$ and the twin $\mathrm{CX}_{9} \mathrm{C}$ motif-containing chaperones involved in $\mathrm{Cu}$ delivery to the COX active sites, and this is illustrated by the fact that yeast $\mathrm{Sco} 1$ and $\mathrm{Sco} 2$ were originally identified as suppressors of Cox17 deficiency (Moira Glerum et al., 1996b). However, contrary to Sco1, the lack of Sco2 did not affect COX (Moira Glerum et al., 1996b). This differs from human mitochondria, where defects in both SCO1 and SCO2 result in CIV deficiency and pathological mutations in both these genes are associated with manifestations of mitochondrial diseases (Papadopoulou et al., 1999; Jaksch et al., 2000; Valnot et al., 2000; Leary et al., 2004; Fernandez-Vizarra and Zeviani, 2021). In human cells, SCO1 and SCO 2 have non-overlapping cooperative roles in $\mathrm{MT}-\mathrm{CO} 2$ maturation, where $\mathrm{SCO} 2$ acts upstream of SCO1 oxidizing its $\mathrm{Cu}$-binding Cys residues during the process of $\mathrm{Cu}$ delivery to MT-CO2 (Leary et al., 2004, Leary et al., 2009). The importance of these processes not only for COX biogenesis but for other aspects of cellular health, is pointed out by the fact that functional SCO1 and SCO2 are required to maintain $\mathrm{Cu}$ homeostasis (Leary et al., 2007; Cobine et al., 2021).

\section{REACTIVE OXYGEN SPECIES-REGULATED ASSEMBLY AND TURNOVER OF THE ETC COMPLEXES}

The production of ROS is inherent to the aerobic metabolic routes located in mitochondria (Murphy, 2009; Brand, 2016). These ROS are mainly superoxide $\left(\mathrm{O}_{2}{ }^{-}\right)$, the majority of which is produced at the levels of complexes I and III (Brand, 2010, 2016), which is subsequently dismutated to hydrogen peroxide $\left(\mathrm{H}_{2} \mathrm{O}_{2}\right)$, and the highly reactive and unstable hydroxyl radical $(\mathrm{OH})$, produced through the Fenton reaction (Lambert and Brand, 2009). Mitochondria also produce other redox active compounds such as reactive nitrogen species (RNS), mainly nitric oxide (NO) (Ghafourifar and Cadenas, 2005), or $\mathrm{H}_{2} \mathrm{~S}$ (Kimura et al., 2010; Paul et al., 2021), which induce modifications of Cys in proteins, modulating their activities (Habich et al., 2019b). However, discussion of these species is beyond the scope of this review, which focuses on ROS directly produced by the ETC (Figure 5), due to electrons slipping off of the system and escaping from the redox active centers to partially reduce oxygen. The idea that ROS are only harmful molecules leading to detrimental effects for the cell and causing different diseases and aging, is now changing (Scialò et al., 2017; Ji and Yeo, 2021). Nowadays, ROS are recognized as signaling molecules mediating a myriad of cellular responses (Holmström and Finkel, 2014; Reczek and Chandel, 2015). However, in parallel, cells have had to develop antioxidant defense systems to protect themselves from ROS overaccumulation and oxidative damage, whilst these antioxidant systems themselves might be involved in the ROSmediated signaling as well (Holmström and Finkel, 2014; Reczek and Chandel, 2015). Consequently, a correct balance between ROS production and scavenging is important to ensure the appropriate cellular responses while preventing oxidative stress (Ji and Yeo, 2021). In fact, a moderate production of ROS is the basis of the phenomenon called "mitohormesis" leading to a stress adaptive response and ultimately to improved mitochondrial function and life extension (Schulz et al., 2007; Palmeira et al., 2019). In addition, it is becoming evident that ROS produced in the mitochondria play an important role in mediating mitochondrial biogenesis to compensate for ETC dysfunction (Dogan et al., 2018).

Superoxide radicals produced by $\mathrm{CIII}_{2}$ and glycerol-3phosphate dehydrogenase $(\mathrm{GPDH})$ are generated in both sides of the IM (the IMS and the matrix), whereas, all the other sites produce ROS in the matrix (Brand, 2010; Figure 5). In addition, ALR (Erv1) seems to be a significant contributor of $\mathrm{O}_{2}{ }^{-}$radicals within the IMS (Daithankar et al., 2012). $\mathrm{O}_{2}{ }^{-}$ produced in the matrix side is dismutated to $\mathrm{H}_{2} \mathrm{O}_{2}$ by the mitochondrial Mn superoxide dismutase (SOD2) and can then diffuse to the cytosol (Boveris et al., 2006; Murphy, 2009), whereas, that released into the IMS can be transported through voltage-dependent ion channels into the cytosol (Han et al., 2003; Muller et al., 2004). Once in there, the $\mathrm{Cu}, \mathrm{Zn}$ superoxide dismutase (SOD1) converts it to $\mathrm{H}_{2} \mathrm{O}_{2}$. SOD1 is dually localized in the cytosol and the IMS in mammals and yeast, and the IMS pool appears to be inactive in basal conditions and activated by modulating its redox state (Iñarrea et al., 2005, 2007). $\mathrm{H}_{2} \mathrm{O}_{2}$ in the cytosol is then able to modify the redox state of key Cys residues in target proteins, modulating the function of factors such as signaling regulatory kinases and phosphatases or transcription factors (Holmström and Finkel, 2014; Reczek and Chandel, 2015).

There are three aspects in which ROS production in mitochondria may influence directly the biogenesis and function of the ETC complexes: (1) by generating oxidation in the IMS and inducing changes in the redox state of key Cys residues and thus, in the structure and function of the redox-sensitive biogenesis factors; (2) the role of ROS produced inside mitochondria as signaling molecules to regulate ETC biogenesis; and (3) ROS-mediated protease 


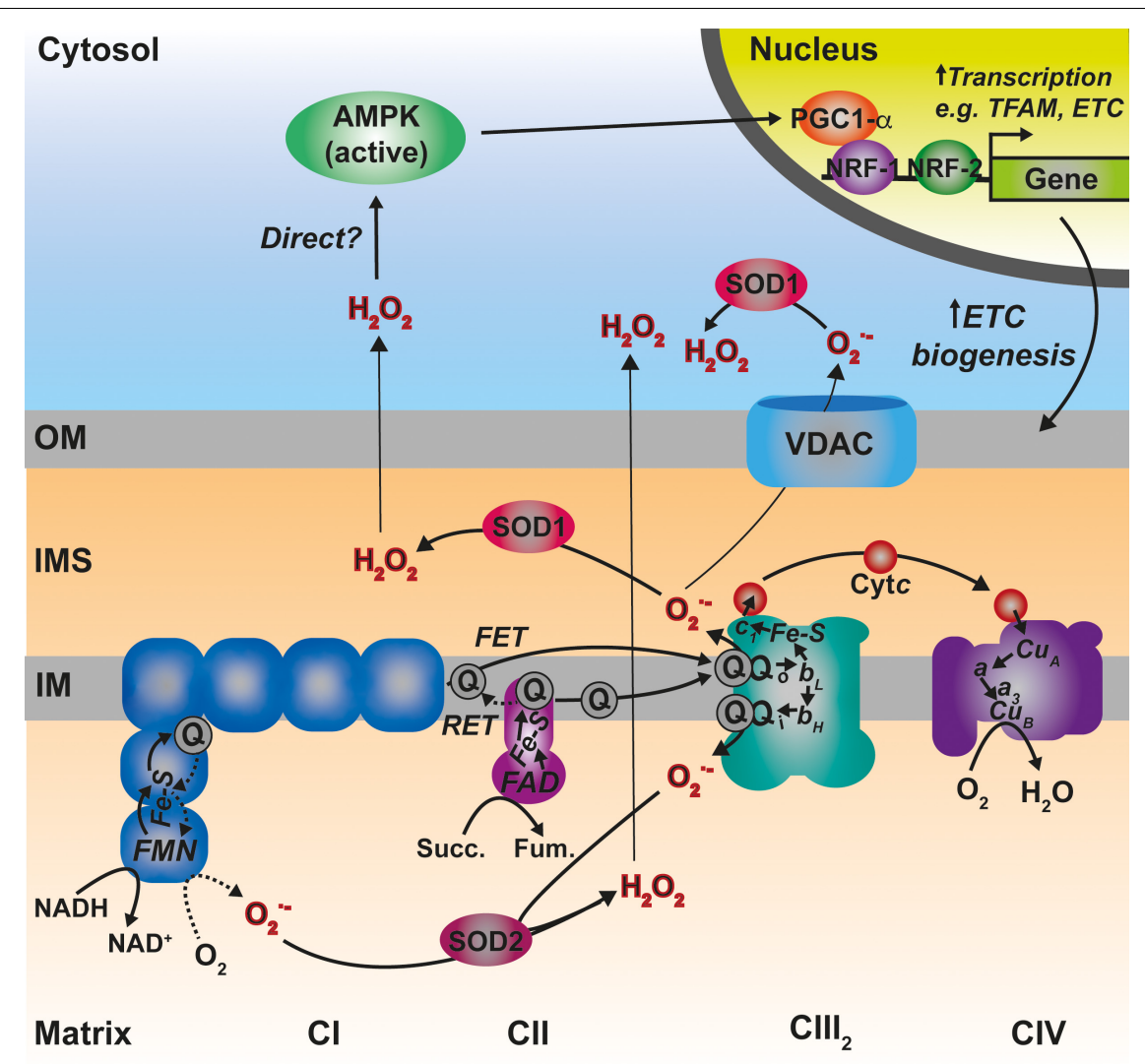

FIGURE 5 | Main sites of ROS generation by the ETC and possible pathways of ROS-mediated regulation of mitochondrial biogenesis. Complex I (CI) represented in blue, generates superoxide $\left(\mathrm{O}_{2}^{-}\right)$both via forward electron transfer (FET) or reverse electron transfer (RET) from a highly reduced coenzyme $\mathrm{Q}$ ( $\mathrm{Q}$ ) pool and high membrane potential. Two other prominent sites of $\mathrm{O}_{2}-$ production are the two $\mathrm{Q}$ binding sites in $\mathrm{Clll} 2(\mathrm{Qo}$ and $\mathrm{Qi})$. $\mathrm{O}_{2}-$ is dismutated to hydrogen peroxide $\left(\mathrm{H}_{2} \mathrm{O}_{2}\right)$ by the two differently localized superoxide dismutases SOD1 and SOD2. See main text for details.

activation inducing the degradation of components of the ETC complexes.

\section{Redox Homeostasis in the IMS and Regulation of ETC Biogenesis}

Given the essentiality of the Cys-containing subunits and assembly factors of the ETC complexes, a correct redox homeostasis in the IMS is crucial for the biogenesis of the respiratory complexes. Thus, it is important to maintain the redox sensitive residues in the correct oxidation state for import and retention in the IMS, as well as for protein function (Habich et al., 2019a; Dickson-Murray et al., 2021). Considering the number of redox regulated IMS-located factors involved, this is particularly relevant for the assembly and metalation of CIV (Khalimonchuk and Winge, 2008; Jett and Leary, 2018). Although there are still many open questions as to how the IMS maintains its redox homeostasis (Dickson-Murray et al., 2021), it is clear that it contains several systems that ensure it, having glutathione as a central component (Calabrese et al., 2017). One such mechanism for maintaining homeostasis in this compartment is the retro-translocation of reduced proteins back into the cytosol through the Tom40 import pore protein. This provides a means to regulate the abundance of IMS proteins either in response to various changes in cellular physiology or for the removal of misfolded proteins by presenting them to protein quality control machineries located in the cytosol (Bragoszewski et al., 2015). Surprisingly, the IMS is not as oxidizing as one would expect, being the glutathione pools as highly reduced in yeast and human mitochondria as in the cytosol (Kojer et al., 2012; Fischer et al., 2013). In such a reducing environment, the essential oxidative folding pathway is maintained by limiting glutaredoxin (Grx) activity in the IMS (Kojer et al., 2015). As mentioned before, the IMS, where most of the Cys-rich redox sensitive proteins reside, receives significant amounts of ROS. $\mathrm{H}_{2} \mathrm{O}_{2}$ oxidizes target thiols of the Cys residues to form disulfide bonds, but also to higher oxidation states such as sulfenic, sulfinic and sulfonic acids, changing the functional properties of the Cys-containing proteins (Habich et al., 2019b). Sulfonylation is irreversible and sulfinylation was thought to be as well until an enzyme called sulfiredoxin (Srx) was identified in yeast and humans, catalyzing the reduction of Cys sulfinic acids in vivo (Jacob et al., 2004). Enzymes aimed to detoxify $\mathrm{H}_{2} \mathrm{O}_{2}$ and/or remove thiol modifications have been found in the IMS of both yeast and human mitochondria (Vögtle et al., 2012; Hung et al., 2014). Peroxiredoxins 3 and 4 (PRDX3 and 4) react directly 
with $\mathrm{H}_{2} \mathrm{O}_{2}$, reducing it to water, resulting in the oxidation of Cys residues that can be reduced again by thioredoxin 1 (TRX1), TRX1 is then recycled by Thioredoxin reductase (TRR) (Cardenas-Rodriguez and Tokatlidis, 2017; Habich et al., 2019b). In addition, glutathione peroxidase $3(\mathrm{Gpx} 3)$ is found in the IMS, where it becomes actively targeted to through the addition of an N-terminal extension of 18 amino acids (N18) and is thought to play a role in $\mathrm{H}_{2} \mathrm{O}_{2}$ detoxification (Kritsiligkou et al., 2017). Translation of this long form of Gpx3 with the $\mathrm{N} 18$ extension can be modulated by $\mathrm{H}_{2} \mathrm{O}_{2}$ stress (Gerashchenko et al., 2012). The cytoplasmic isoform of GPX4, the human homolog of Gpx3, has also been found in mitochondria (Liang et al., 2009; Tadokoro et al., 2020) but the role it plays there is still unclear.

\section{ROS-Mediated Signaling Promoting ETC Biogenesis}

In certain situations, dysfunction or inhibition of CI, CIII, or CIV leads to increased ROS production (Verkaart et al., 2007; Kowaltowski et al., 2009; Brand, 2016; Dogan et al., 2018). However, as briefly discussed above, the nature and topology of these ROS is different depending on what complex is affected. In addition, the physio-pathological consequences can also diverge. CI can generate ROS both by "forward electron transfer (FET)" or by "reverse electron transfer (RET)," i.e., by transferring electrons from a highly reduced CoQ pool back to CI, in conditions where the membrane potential is high (Robb et al., 2018; Figure 5). This is relevant because ROS generated at the level of CI, but only if its via RET, are able to induce an adaptive program leading to improved mitochondrial activity and increased life span in D. melanogaster (Scialò et al., 2016). $\mathrm{O}^{-}$generated at the level of the first CoQ binding site of $\mathrm{CIII}_{2}\left(\mathrm{Q}_{o}\right)$, closest to the IMS, has been described to be the origin of signaling pathways such as the hypoxic responses (Guzy et al., 2005; Bell et al., 2007). At the mitochondrial level, the ROS-mediated hypoxic transcriptional program leads to the expression of specific COX isoforms, regulating the activity of the complex under these conditions (Bourens et al., 2013). Also, ROS produced in the mitochondria activate AMPK, which activates PGC- $1 \alpha$, a transcriptional master regulator of mitochondrial biogenesis (Jäer et al., 2007; Rabinovitch et al., 2017; Figure 5). This ROS-mediated signaling axis is necessary to induce an increase in mitochondrial mass to counteract CIV deficiency in muscle (Dogan et al., 2018). Apart from these mitochondrial remodeling effects mediated by transcriptional changes, an attractive possibility is that ROS produced in the mitochondria can directly modulate the activity of biogenetical factors such as COA8 (Figure 6). The absence of COA8 (formerly known as APOPT1) leads to CIV deficiency and the accumulation of MT-CO1-containing partially assembled species (Melchionda et al., 2014; Signes and Fernandez-Vizarra, 2018).

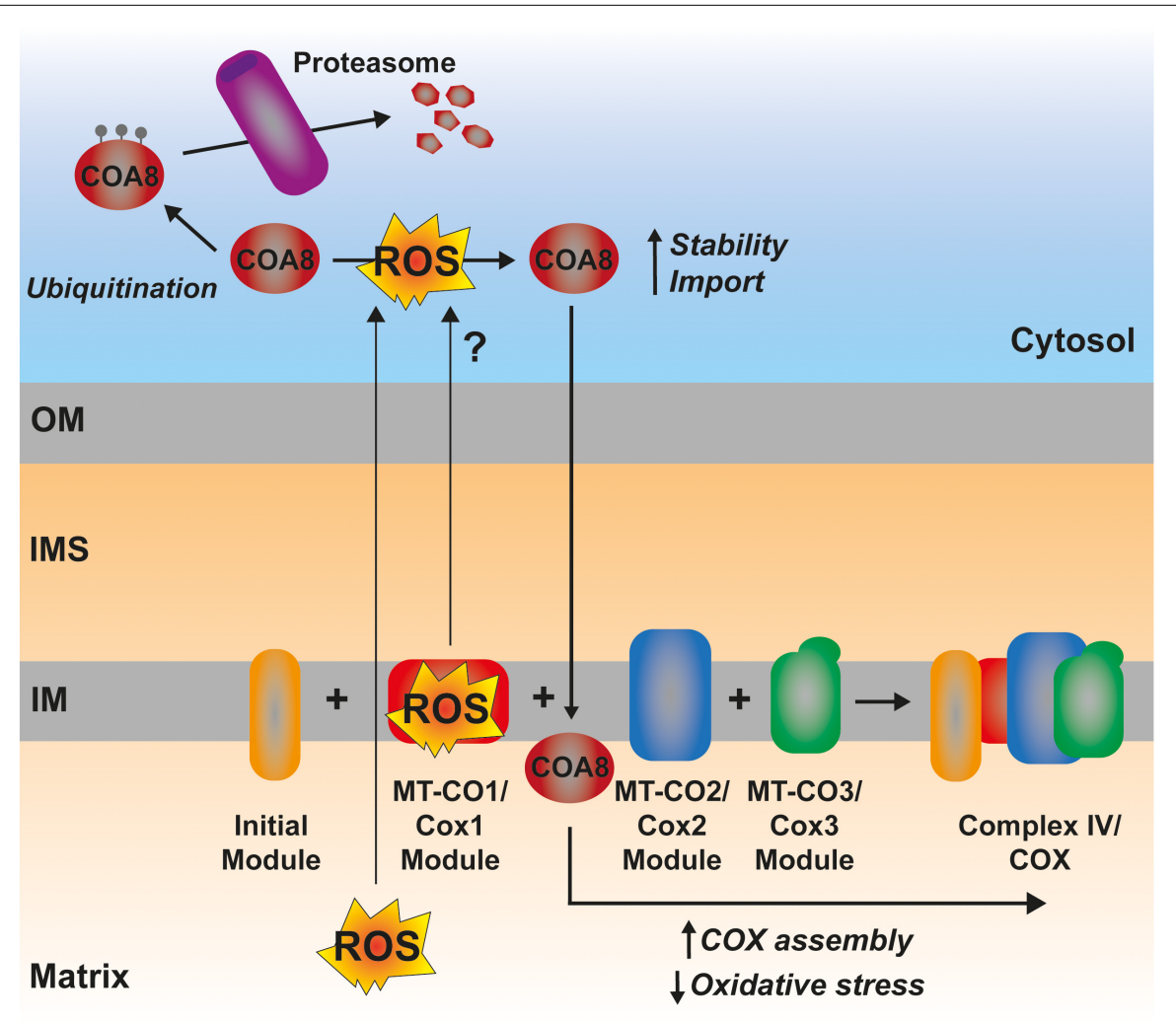

FIGURE 6 | Possible mechanism of ROS-mediated CIV assembly regulation by COA8. The ROS produced by a hemylated partially assembled MT-CO1 could represent a signal triggering the increased import and/or stabilization of COA8, promoting CIV assembly and, thereby, reducing oxidative stress. 
COA8 was shown to be readily degraded by the proteasome in the cytosol but stabilized inside mitochondria when cells were stressed with both exogenous $\mathrm{H}_{2} \mathrm{O}_{2}$ or with mitochondrially targeted paraquat (mitoPQ), which induces the production of $\mathrm{O}_{2}{ }^{-}$in the matrix (Signes and Fernandez-Vizarra, 2018). The COA8 sequence contains Cys residues within the mitochondrial targeting sequence that could potentially be oxidized by $\mathrm{H}_{2} \mathrm{O}_{2}$ in the cytosol, inducing its stabilization and/or mitochondrial import (Signes and Fernandez-Vizarra, 2018). Yeast strains deleted of Scol or Cox11 show increased sensitivity to acute hydrogen peroxide stress (Khalimonchuk et al., 2007; Veniamin et al., 2011). This effect was linked to impaired COX assembly leading to the accumulation of hemylated Cox1 intermediates acting as pro-oxidant species (Khalimonchuk et al., 2007). Interestingly, COA8-null patient derived fibroblasts produce more ROS when they are oxidatively challenged (Melchionda et al., 2014) and $d$ Coa 8 knock-down flies are more sensitive to oxidative stress (Brischigliaro et al., 2019). A hypothesis that can be derived from these observations is that ROS produced because of the accumulation of pro-oxidant MT-CO1 subcomplexes serve as a signal to induce the assembly of CIV mediated by COA8, which also appeared to have a role in protecting MT-CO1 from oxidative stress induced degradation (Signes and Fernandez-Vizarra, 2018). More experimental data must be collected to confirm or disprove these ideas and to determine whether there are more redox sensitive assembly factors for CIV and the rest of the complexes, which may be regulated in this way to promote a rapid biogenetical response to regulate ETC function.

\section{ROS-Mediated Degradation of ETC Components}

A much less explored yet interesting component in the control of the amounts and function of the ETC is the turnover, i.e., balance between synthesis and degradation, of its components (Szczepanowska and Trifunovic, 2021). In yeast, the accumulation of pro-oxidant COX subcomplexes is attenuated by the activity of the AAA-ATPase Afg1, facilitating the degradation of Cox1, Cox2, and Cox3 (Khalimonchuk et al., 2007; Figure 7). Afg1 human ortholog is LACE1, and it was shown to be involved in the degradation of nuclear-encoded CIV subunits (Cesnekova et al., 2016). As mentioned earlier, Cox1 accumulated due to the absence of the assembly factor Coa2 is degraded by Oma1 (Khalimonchuk et al., 2012) and Omal is redox regulated both in yeast and human mitochondria (Bohovych et al., 2019). Also in human mitochondria, in the case of defective CIV assembly at different stages with the accumulation of MT-CO1 module subassemblies, is associated with an increased turnover of the mtDNA-encoded CIV subunits (Leary et al., 2009; Bourens et al., 2014; Bourens and Barrientos, 2017a,b; Signes and FernandezVizarra, 2018). Another ETC component in mammals, whose turnover is potentially regulated by ROS is CI (Figure 7). The assembly of this huge complex happens in a modular

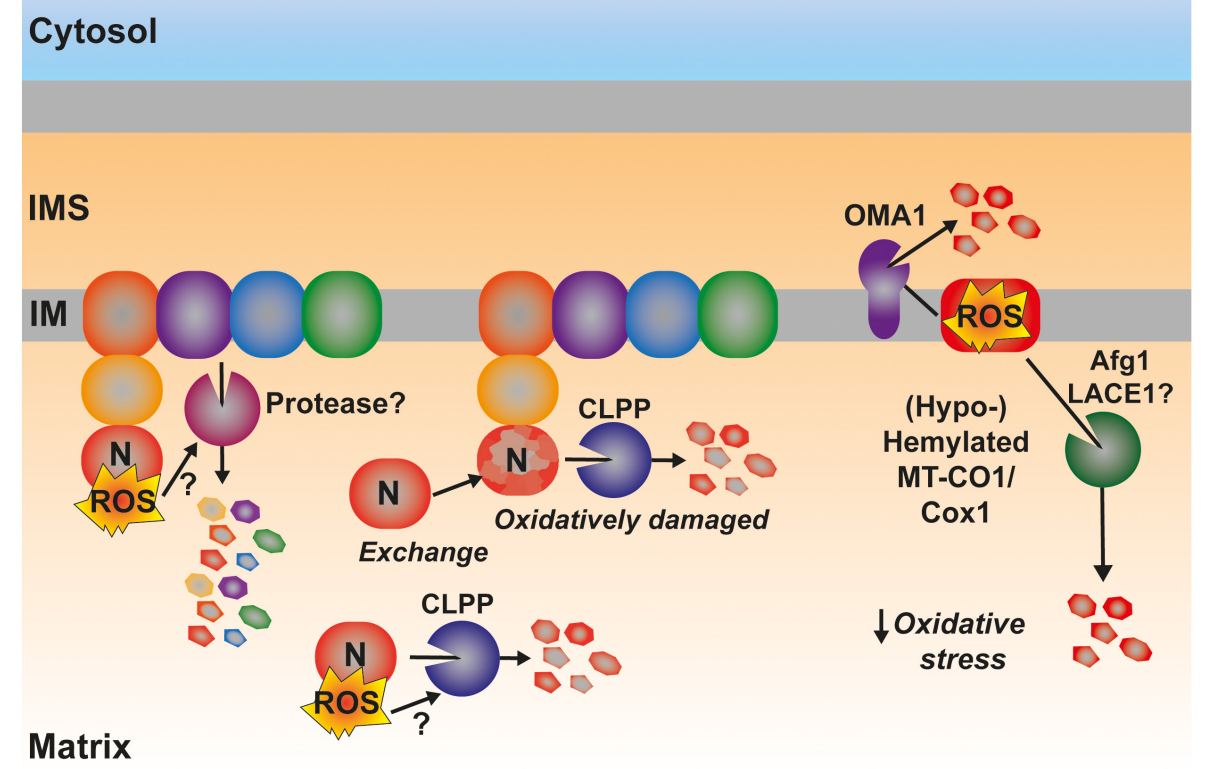

FIGURE 7 | Possible involvement of ROS in the regulation of the degradation by active proteolysis of some of the catalytical components of the ETC. ROS produced by RET at the level of $\mathrm{Cl}$ have been proposed to trigger the degradation of the full complex. The mechanistic details are still unknown. The matrix protease CLPP is responsible for the degradation of the catalytic $\mathrm{N}$-module of $\mathrm{Cl}$, preventing its accumulation as an assembly intermediate in the mitochondrial matrix as well as promoting the interchange of an oxidatively damaged $\mathrm{N}$-module for a newly synthesized one. Some Cox1 (MT-CO1) intermediates are actively degraded by the inner membrane-bound protease OMA1, which is redox activated. Other pro-oxidant Cox1 intermediates are degraded through a mechanism mediated by the AAA-ATPase Afg1 in yeast being LACE1 its human ortholog. See main text for details. 
fashion and the $\mathrm{N}$-module containing the redox active Fe-S clusters and flavin (FMN) is preassembled and then added in the last step of assembly (Guerrero-Castillo et al., 2017). CLPP is responsible for the turnover of both the pre-assembled and assembled N-module (Szczepanowska et al., 2020). In this case, one could think that this might be a way of preventing the accumulation of a highly reactive pro-oxidant species and to remove oxidatively damaged protein components in proximity to the N-module FMN center, which is one of the main sites of ROS production in mitochondria (Brand, 2016; Hirst and Roessler, 2016). Then again, mammalian CI shows a high interdependence with the other components of the ETC. Strong $\mathrm{CIII}_{2}$ and CIV assembly defects produce a secondary decline in CI amounts (Diaz et al., 2006; Protasoni et al., 2020; Čunátová et al., 2021). This was explained by the existence of an active degradation of fully assembled CI in response to RET-mediated ROS production and oxidative damage (Guarás et al., 2016). However, the exact mechanism and the protease/s mediating this accelerated turnover have not been defined yet, and other levels of regulation, i.e., repression of mitochondrial translation and attenuated assembly of the $\mathrm{N}$-module, have been shown (Protasoni et al., 2020; Cunátová et al., 2021). In the case of the $\mathrm{CIII}_{2}$ defects originated by mutations in the central subunit MT$\mathrm{CYB}$, mitochondrial translation was not affected (Protasoni et al., 2020; Tropeano et al., 2020). However, the steady-state levels of CI subunits and specially those of the $\mathrm{N}$-module were severely reduced (Protasoni et al., 2020; Páleníková et al., 2021). One can imagine that if the $\mathrm{N}$-module is being preassembled but not incorporated into fully assembled CI, it will need to be degraded before its assembly, as previously shown (Szczepanowska et al., 2020). One can hypothesize that this might be ROS mediated and induced by a pro-oxidant intermediate, because xenoexpression of an alternative oxidase (AOX), which decreases ROS production by the ETC (Dogan et al., 2018; Robb et al., 2018; Szibor et al., 2020), resulted in increased amounts of N-module subunits and fully assembled CI in MT-CYB mutated human cells (Protasoni et al., 2020).

Whether the enhanced proteolysis of the redox active, and potentially damaging, CI and CIV subassemblies is directly modulated by ROS, and which are quality control proteases that are involved and regulated in this way, constitute extremely interesting topics to explore in the future.

\section{CONCLUSION AND PERSPECTIVES}

Mitochondria contain dedicated import and sorting machineries to direct mitochondrial proteins that are nuclear encoded and synthesized in the cytoplasm. The MIA pathway makes use of reduction and oxidation reactions involving particular

\section{REFERENCES}

Abdulhag, U. N., Soiferman, D., Schueler-Furman, O., Miller, C., Shaag, A., Elpeleg, O., et al. (2015). Mitochondrial complex IV deficiency, caused by mutated COX6B1, is associated with encephalomyopathy, hydrocephalus and cardiomyopathy. Eur. J. Hum. Genet. 23, 159-164. doi: 10.1038/ejhg.2014.85
Cys residues so that the correctly folded and functional proteins are retained in the IMS. Therefore, redox homeostasis in the IMS plays a crucial role in the regulation of the ETC complexes because essential factors involved in their maturation are proteins containing twin $\mathrm{Cx}_{9} \mathrm{C}$ motifs and substrates of Mia40/CHCHD4. In order to guarantee a correct ETC biogenesis, redox homeostasis of the IMS needs to be maintained in spite of its proximity to the ETC. The ETC contains major sites of ROS production, which were traditionally envisioned as merely harmful molecules contributing to aging and disease. It is now becoming clearer that an exquisite balance between ROS production and scavenging is essential to maintain mitochondrial activity. Another emerging concept is that they constitute signaling molecules important for a correct mitochondrial biogenesis, mediating feedback mechanisms regulating the biogenesis and degradation of ETC components. The mechanisms and players underlying these phenomena are just starting to be unraveled. In this respect, an interesting hypothesis to explore is the fact that ROS might be a sensor of unbalanced ETC activity, triggering mechanisms aimed to compensate it, through biogenetical factors and proteases whose activity is directly redox regulated.

\section{AUTHOR CONTRIBUTIONS}

SG and EF-V wrote the first draft and produced the figures and table. EF-V and KT coordinated the writing. KT obtained funding. All authors edited the final version.

\section{FUNDING}

Work in our laboratory was supported by UKRI-BBSRC (grants BB/R009031/1 and BB/T003804/1) and a BBSRC-EPSRC Impact Accelerator grant and a Wellcome Trust early concept development grant (University of Glasgow). Structural biology work in our laboratory benefited from access to the Solution NMR, CERM/CIRMMP, Florence, Italy, an Instruct-ERIC center. Financial support was provided by Instruct-ERIC (PID: 12148).

\section{ACKNOWLEDGMENTS}

We thank Paul A. Cobine (Auburn University, Auburn, AL, United States), Scot C. Leary (University of Saskatchewan, Saskatoon, SK, Canada), Oleh Khalimonchuk (University of Nebraska, Lincoln, NE, United States), David Pacheu-Grau (University of Zaragoza, Spain), and the members of our lab for helpful discussions and comments on the manuscript.

Aich, A., Wang, C., Chowdhury, A., Ronsör, C., Pacheu-Grau, D., RichterDennerlein, R., et al. (2018). COX16 promotes COX2 metallation and assembly during respiratory complex IV biogenesis. Elife 7:32572. doi: 10.7554/eLife. 32572

Allen, S., Balabanidou, V., Sideris, D. P., Lisowsky, T., and Tokatlidis, K. (2005). Erv1 mediates the Mia40-dependent protein import pathway and provides a 
functional link to the respiratory chain by shuttling electrons to cytochrome c. J. Mol. Biol. 353, 937-944. doi: 10.1016/j.jmb.2005.08.049

Alston, C. L., Veling, M. T., Heidler, J., Taylor, L. S., Alaimo, J. T., Sung, A. Y., et al. (2020). Pathogenic Bi-allelic Mutations in NDUFAF8 Cause Leigh Syndrome with an Isolated Complex I Deficiency. Am. J. Hum. Genet. 106, 92-101. doi: 10.1016/j.ajhg.2019.12.001

Amaravadi, R., Glerum, D. M., and Tzagoloff, A. (1997). Isolation of a cDNA encoding the human homolog of COX17, a yeast gene essential for mitochondrial copper recruitment. Hum. Genet. 99, 329-333. doi: 10.1007/ s004390050367

Anand, R., Wai, T., Baker, M. J., Kladt, N., Schauss, A. C., Rugarli, E., et al. (2014). The i-AAA protease YME1L and OMA1 cleave OPA1 to balance mitochondrial fusion and fission. J. Cell Biol. 204, 919-929. doi: 10.1083/jcb.201308006

Araiso, Y., Imai, K., and Endo, T. (2020). Structural snapshot of the mitochondrial protein import gate. FEBS J. doi: 10.1111/febs.15661

Araiso, Y., Tsutsumi, A., Qiu, J., Imai, K., Shiota, T., Song, J., et al. (2019). Structure of the mitochondrial import gate reveals distinct preprotein paths. Nature 575, 395-401. doi: 10.1038/s41586-019-1680-7

Backes, S., Hess, S., Boos, F., Woellhaf, M. W., Gödel, S., Jung, M., et al. (2018). Tom70 enhances mitochondrial preprotein import efficiency by binding to internal targeting sequences. J. Cell Biol. 217, 1369-1382. doi: 10.1083/jcb. 201708044

Baertling, F., van den, A. M., Brand, M., Hertecant, J. L., Al-Shamsi, A., van den, P., et al. (2015). Mutations in COA6 cause cytochrome c oxidase deficiency and neonatal hypertrophic cardiomyopathy. Hum. Mutat. 36, 34-38. doi: 10.1002/ humu. 22715

Baker, M. J., Lampe, P. A., Stojanovski, D., Korwitz, A., Anand, R., Tatsuta, T., et al. (2014). Stress-induced OMA1 activation and autocatalytic turnover regulate OPA1-dependent mitochondrial dynamics. EMBO J. 33, 578-593. doi: 10.1002/ embj.201386474

Baker, M. J., Mooga, V. P., Guiard, B., Langer, T., Ryan, M. T., and Stojanovski, D. (2012). Impaired folding of the mitochondrial small TIM chaperones induces clearance by the i-AAA protease. J. Mol. Biol. 424, 227-239. doi: 10.1016/j.jmb. 2012.09.019

Ban, R., Liu, Z., Shimura, M., Tong, X., Wang, J., Yang, L., et al. (2021). Biallelic COA7-Variants Leading to Developmental Regression With Progressive Spasticity and Brain Atrophy in a Chinese Patient. Front. Genet. 12, 1-8. doi: $10.3389 /$ fgene.2021.685035

Ban, T., Ishihara, T., Kohno, H., Saita, S., Ichimura, A., Maenaka, K., et al. (2017). Molecular basis of selective mitochondrial fusion by heterotypic action between OPA1 and cardiolipin. Nat. Cell Biol. 19, 856-863. doi: 10.1038/ncb3560

Banci, L., Bertini, I., Calderone, V., Cefaro, C., Ciofi-Baffoni, S., Gallo, A., et al. (2011a). Molecular recognition and substrate mimicry drive the electrontransfer process between MIA40 and ALR. Proc. Natl. Acad. Sci. U. S. A. 108, 4811-4816. doi: 10.1073/pnas.1014542108

Banci, L., Bertini, I., Calderone, V., Cefaro, C., Ciofi-Baffoni, S., Gallo, A., et al. (2012). An electron-transfer path through an extended disulfide relay system: The case of the redox protein ALR. J. Am. Chem. Soc. 134, 1442-1445. doi: 10.1021/ja209881f

Banci, L., Bertini, I., Cantini, F., Ciofi-Baffoni, S., Gonnelli, L., and Mangani, S. (2004). Solution structure of Cox11, a novel type of $\beta$-immunoglobulin-like fold involved in $\mathrm{CuB}$ site formation of cytochrome c oxidase. J. Biol. Chem. 279, 34833-34839. doi: 10.1074/jbc.M403655200

Banci, L., Bertini, I., Cefaro, C., Ciofi-Baffoni, S., Gajda, K., Felli, I. C., et al. (2013). An intrinsically disordered domain has a dual function coupled to compartment-dependent redox control. J. Mol. Biol. 425, 594-608. doi: 10.1016/ j.jmb.2012.11.032

Banci, L., Bertini, I., Cefaro, C., Ciofi-Baffoni, S., and Gallo, A. (2011b). Functional role of two interhelical disulfide bonds in human Cox17 protein from a structural perspective. J. Biol. Chem. 286, 34382-34390. doi: 10.1074/jbc.M111. 246223

Banci, L., Bertini, I., Cefaro, C., Ciofi-Baffoni, S., Gallo, A., Martinelli, M., et al. (2009). MIA40 is an oxidoreductase that catalyzes oxidative protein folding in mitochondria. Nat. Struct. Mol. Biol. 16, 198-206. doi: 10.1038/nsmb.1553

Banci, L., Bertini, I., Ciofi-Baffoni, S., Hadjiloi, T., Martinelli, M., and Palumaa, P. (2008a). Mitochondrial copper(I) transfer from Cox17 to Scol is coupled to electron transfer. Proc. Natl. Acad. Sci. U. S. A. 105, 6803-6808. doi: 10.1073/ pnas. 0800019105
Banci, L., Bertini, I., Ciofi-Baffoni, S., Janicka, A., Martinelli, M., Kozlowski, H., et al. (2008b). A structural-dynamical characterization of human Cox17. J. Biol. Chem. 283, 7912-7920. doi: 10.1074/jbc.M70801 6200

Barros, M. H., Johnson, A., and Tzagoloff, A. (2004). COX23, a homologue of COX17, is required for cytochrome oxidase assembly. J. Biol. Chem. 279, 31943-31947. doi: 10.1074/jbc.M405014200

Becker, T., Wenz, L. S., Krüger, V., Lehmann, W., Müller, J. M., Goroncy, L., et al. (2011). The mitochondrial import protein Mim1 promotes biogenesis of multispanning outer membrane proteins. J. Cell Biol. 194, 387-395. doi: 10.1083/jcb.201102044

Beers, J., Glerum, D. M., and Tzagoloff, A. (1997). Purification, characterization, and localization of yeast Cox17p, a mitochondrial copper shuttle. J. Biol. Chem. 272, 33191-33196. doi: 10.1074/jbc.272.52.33191

Bell, E. L., Klimova, T. A., Eisenbart, J., Moraes, C. T., Murphy, M. P., Budinger, G. R. S., et al. (2007). The Qo site of the mitochondrial complex III is required for the transduction of hypoxic signaling via reactive oxygen species production. J. Cell Biol. 177, 1029-1036. doi: 10.1083/jcb.200609074

Bénit, P., Goncalves, S., Dassa, E. P., Brière, J. J., and Rustin, P. (2008). The variability of the Harlequin mouse phenotype resembles that of human mitochondrial-complex I-deficiency syndromes. PLoS One 3:3208. doi: 10.1371/ journal.pone. 0003208

Bestwick, M., Jeong, M.-Y., Khalimonchuk, O., Kim, H., and Winge, D. R. (2010a). Analysis of Leigh Syndrome Mutations in the Yeast SURF1 Homolog Reveals a New Member of the Cytochrome Oxidase Assembly Factor Family. Mol. Cell. Biol. 30, 4480-4491. doi: 10.1128/mcb.00228-10

Bestwick, M., Khalimonchuk, O., Pierrel, F., and Winge, D. R. (2010b). The Role of Coa2 in Hemylation of Yeast Cox1 Revealed by Its Genetic Interaction with Cox10. Mol. Cell. Biol. 30, 172-185. doi: 10.1128/mcb.00869-09

Beverly, K. N., Sawaya, M. R., Schmid, E., and Koehler, C. M. (2008). The Tim8Tim13 Complex Has Multiple Substrate Binding Sites and Binds Cooperatively to Tim23. J. Mol. Biol. 382, 1144-1156. doi: 10.1016/j.jmb.2008.07.069

Bode, M., Longen, S., Morgan, B., Peleh, V., Dick, T. P., Bihlmaier, K., et al. (2013). Inaccurately assembled cytochrome $c$ oxidase can lead to oxidative stress-induced growth arrest. Antioxidants Redox Signal. 18, 1597-1612. doi: 10.1089/ars.2012.4685

Bode, M., Woellhaf, M. W., Bohnert, M., Van Der Laan, M., Sommer, F., Jung, M., et al. (2015). Redox-regulated dynamic interplay between Cox19 and the copper-binding protein Cox11 in the intermembrane space of mitochondria facilitates biogenesis of cytochrome c oxidase. Mol. Biol. Cell 26, 2385-2401. doi: 10.1091/mbc.E14-11-1526

Bohovych, I., Dietz, J. V., Swenson, S., Zahayko, N., and Khalimonchuk, O. (2019). Redox Regulation of the Mitochondrial Quality Control Protease Oma1. Antioxidants Redox Signal. 31, 429-443. doi: 10.1089/ars.2018.7642

Bohovych, I., Donaldson, G., Christianson, S., Zahayko, N., and Khalimonchuk, O. (2014). Stress-triggered activation of the metalloprotease Omal involves its C-terminal region and is important for mitochondrial stress protection in yeast. J. Biol. Chem. 289, 13259-13272. doi: 10.1074/jbc.M113.54 2910

Bohovych, I., Fernandez, M. R., Rahn, J. J., Stackley, K. D., Bestman, J. E., Anandhan, A., et al. (2015). Metalloprotease OMA1 Fine-tunes Mitochondrial Bioenergetic Function and Respiratory Supercomplex Stability. Sci. Rep. 5:13989. doi: 10.1038/srep13989

Bourens, M., and Barrientos, A. (2017a). A CMC 1 -knockout reveals translationindependent control of human mitochondrial complex IV biogenesis. EMBO Rep. 18, 477-494. doi: 10.15252/embr.201643103

Bourens, M., and Barrientos, A. (2017b). Human mitochondrial cytochrome c oxidase assembly factor COX18 acts transiently as a membrane insertase within the subunit 2 maturation module. J. Biol. Chem. 292, 7774-7783. doi: 10.1074/ jbc.M117.778514

Bourens, M., Boulet, A., Leary, S. C., and Barrientos, A. (2014). Human COX20 cooperates with $\mathrm{SCO} 1$ and $\mathrm{SCO} 2$ to mature $\mathrm{COX} 2$ and promote the assembly of cytochrome c oxidase. Hum. Mol. Genet. 23, 2901-2913. doi: 10.1093/hmg/ ddu003

Bourens, M., Dabir, D. V., Tienson, H. L., Sorokina, I., Koehler, C. M., and Barrientos, A. (2012). Role of twin Cys-Xaa9-Cys motif cysteines in mitochondrial import of the cytochrome $\mathrm{c}$ oxidase biogenesis factor Cmc1. J. Biol. Chem. 287, 31258-31269. doi: 10.1074/jbc.M112.383562 
Bourens, M., Fontanesi, F., Soto, I. C., Liu, J., and Barrientos, A. (2013). Redox and reactive oxygen species regulation of mitochondrial cytochrome $\mathrm{C}$ oxidase biogenesis. Antioxidants Redox Signal. 19, 1940-1952. doi: 10.1089/ars.2012. 4847

Boveris, A., Valdez, L. B., Zaobornyj, T., and Bustamante, J. (2006). Mitochondrial metabolic states regulate nitric oxide and hydrogen peroxide diffusion to the cytosol. Biochim. Biophys. Acta - Bioenerg. 1757, 535-542. doi: 10.1016/j.bbabio. 2006.02.010

Braems, E., Swinnen, B., and Van Den Bosch, L. (2020). C9orf72 loss-of-function: a trivial, stand-alone or additive mechanism in C9 ALS/FTD? Acta Neuropathol. 140, 625-643. doi: 10.1007/s00401-020-02214-X

Bragoszewski, P., Gornicka, A., Sztolsztener, M. E., and Chacinska, A. (2013). The Ubiquitin-Proteasome System Regulates Mitochondrial Intermembrane Space Proteins. Mol. Cell. Biol. 33, 2136-2148. doi: 10.1128/mcb.01579-12

Bragoszewski, P., Wasilewski, M., Sakowska, P., Gornicka, A., Böttinger, L., Qiu, J., et al. (2015). Retro-translocation of mitochondrial intermembrane space proteins. Proc. Natl. Acad. Sci. U. S. A. 112, 7713-7718. doi: 10.1073/pnas. 1504615112

Brambley, C. A., Marsee, J. D., Halper, N., and Miller, J. M. (2019). Characterization of Mitochondrial YME1L Protease Oxidative Stress-Induced Conformational State. J. Mol. Biol. 431, 1250-1266. doi: 10.1016/j.jmb.2019.01.039

Brand, M. D. (2010). The sites and topology of mitochondrial superoxide production. Exp. Gerontol. 45, 466-472. doi: 10.1016/j.exger.2010.01.003

Brand, M. D. (2016). Mitochondrial generation of superoxide and hydrogen peroxide as the source of mitochondrial redox signaling. Free Radic. Biol. Med. 100, 14-31. doi: 10.1016/j.freeradbiomed.2016.04.001

Brischigliaro, M., Corrà, S., Tregnago, C., Fernandez-Vizarra, E., Zeviani, M., Costa, R., et al. (2019). Knockdown of APOPT1/COA8 Causes Cytochrome c Oxidase Deficiency, Neuromuscular Impairment, and Reduced Resistance to Oxidative Stress in Drosophila melanogaster. Front. Physiol. 10:1143. doi: 10.3389/fphys.2019.01143

Brix, J., Dietmeier, K., and Pfanner, N. (1997). Differential recognition of preproteins by the purified cytosolic domains of the mitochondrial import receptors Tom20, Tom22, and Tom70. J. Biol. Chem. 272, 20730-20735. doi: $10.1074 /$ jbc. 272.33 .20730

Calabrese, G., Morgan, B., and Riemer, J. (2017). Mitochondrial Glutathione: Regulation and Functions. Antioxidants Redox Signal. 27, 1162-1177. doi: 10. 1089/ars.2017.7121

Cardenas-Rodriguez, M., and Tokatlidis, K. (2017). Cytosolic redox components regulate protein homeostasis via additional localisation in the mitochondrial intermembrane space. FEBS Lett. 591, 2661-2670. doi: 10.1002/1873-3468. 12766

Carr, H. S., George, G. N., and Winge, D. R. (2002). Yeast Cox11, a protein essential for cytochrome $\mathrm{c}$ oxidase assembly, is a $\mathrm{Cu}(\mathrm{I})$-binding protein. J. Biol. Chem. 277, 31237-31242. doi: 10.1074/jbc.M204854200

Cesnekova, J., Rodinova, M., Hansikova, H., Houstek, J., Zeman, J., and Stiburek, L. (2016). The mammalian homologue of yeast Afg1 ATPase (lactation elevated 1) mediates degradation of nuclear-encoded complex IV subunits. Biochem. J. 473, 797-804. doi: 10.1042/BJ20151029

Chacinska, A., Pfannschmidt, S., Wiedemann, N., Kozjak, V., Sanjuán Szklarz, L. K., Schulze-Specking, A., et al. (2004). Essential role of Mia40 in import and assembly of mitochondrial intermembrane space proteins. EMBO J. 23, 3735-3746. doi: 10.1038/sj.emboj.7600389

Chacinska, A., van der Laan, M., Mehnert, C. S., Guiard, B., Mick, D. U., Hutu, D. P., et al. (2010). Distinct Forms of Mitochondrial TOM-TIM Supercomplexes Define Signal-Dependent States of Preprotein Sorting. Mol. Cell. Biol. 30, 307-318. doi: 10.1128/mcb.00749-09

Chan, N. C., and Lithgow, T. (2008). The peripheral membrane subunits of the SAM complex function codependently in mitochondrial outer membrane biogenesis. Mol. Biol. Cell 19, 126-136. doi: 10.1091/mbc.E07-080796

Chatzi, A., Sideris, D. P., Katrakili, N., Pozidis, C., and Tokatlidis, K. (2013). Biogenesis of yeast Mia40 - Uncoupling folding from import and atypical recognition features. FEBS J. 280, 4960-4969. doi: 10.1111/febs.12482

Chatzi, A., and Tokatlidis, K. (2013). The mitochondrial intermembrane space: A hub for oxidative folding linked to protein biogenesis. Antioxidants Redox Signal. 19, 54-62. doi: 10.1089/ars.2012.4855
Chung, Y. M., Kim, J. S., Yoo, Y., and Do. (2006). A novel protein, Romo1, induces ROS production in the mitochondria. Biochem. Biophys. Res. Commun. 347, 649-655. doi: 10.1016/j.bbrc.2006.06.140

Cobine, P. A., Moore, S. A., and Leary, S. C. (2021). Getting out what you put in: Copper in mitochondria and its impacts on human disease. Biochim. Biophys. Acta - Mol. Cell Res. 1868:118867. doi: 10.1016/j.bbamcr.2020.118867

Cobine, P. A., Pierrel, F., and Winge, D. R. (2006). Copper trafficking to the mitochondrion and assembly of copper metalloenzymes. Biochim. Biophys. Acta - Mol. Cell Res. 1763, 759-772. doi: 10.1016/j.bbamcr.2006.03.002

Čunátová, K., Reguera, D. P., Vrbacký, M., Fernández-Vizarra, E., Ding, S., Fearnley, I. M., et al. (2021). Loss of COX4I1 Leads to Combined Respiratory Chain Deficiency and Impaired Mitochondrial Protein Synthesis. Cells 10:10020369. doi: 10.3390/cells10020369

Curran, S. P., Leuenberger, D., Leverich, E. P., Hwang, D. K., Beverly, K. N., and Koehler, C. M. (2004). The role of Hot13p and redox chemistry in the mitochondrial TIM22 import pathway. J. Biol. Chem. 279, 43744-43751. doi: 10.1074/jbc.M404878200

Dabir, D. V., Leverich, E. P., Kim, S. K., Tsai, F. D., Hirasawa, M., Knaff, D. B., et al. (2007). A role for cytochrome $\mathrm{c}$ and cytochrome $\mathrm{c}$ peroxidase in electron shuttling from Erv1. EMBO J. 26, 4801-4811. doi: 10.1038/sj.emboj.7601909

Daithankar, V. N., Farrell, S. R., and Thorpe, C. (2009). Augmenter of liver regeneration: Substrate specificity of a flavin-dependent oxidoreductase from the mitochondrial intermembrane space. Biochemistry 48, 4828-4837. doi: 10. 1021/bi900347v

Daithankar, V. N., Wang, W., Trujillo, J. R., and Thorpe, C. (2012). Flavinlinked erv-family sulfhydryl oxidases release superoxide anion during catalytic turnover. Biochemistry 51, 265-272. doi: 10.1021/bi201672h

Darshi, M., Mendiola, V. L., Mackey, M. R., Murphy, A. N., Koller, A., Perkins, G. A., et al. (2011). ChChd3, an inner mitochondrial membrane protein, is essential for maintaining Crista integrity and mitochondrial function. J. Biol. Chem. 286, 2918-2932. doi: 10.1074/jbc.M110.171975

Darshi, M., Trinh, K. N., Murphy, A. N., and Taylor, S. S. (2012). Targeting and import mechanism of coiled-coil helix coiled-coil helix domain-containing protein 3 (ChChd3) into the mitochondrial intermembrane space. J. Biol. Chem. 287, 39480-39491. doi: 10.1074/jbc.M112.387696

Dayan, D., Bandel, M., Günsel, U., Nussbaum, I., Prag, G., Mokranjac, D., et al. (2019). A mutagenesis analysis of Tim50, the major receptor of the TIM23 complex, identifies regions that affect its interaction with Tim23. Sci. Rep. 9:38353. doi: 10.1038/s41598-018-38353-1

Del Dotto, V., Fogazza, M., Carelli, V., Rugolo, M., and Zanna, C. (2018). Eight human OPA1 isoforms, long and short: What are they for? Biochim. Biophys. Acta-Bioenerg. 1859, 263-269. doi: 10.1016/j.bbabio.2018.01.005

Dela Cruz, R., Jeong, M. Y., and Winge, D. R. (2016). Coxl mutation abrogates need for Cox23 in cytochrome c oxidase biogenesis. Microb. Cell 3, 275-284. doi: 10.15698/mic2016.07.511

Delavallée, L., Mathiah, N., Cabon, L., Mazeraud, A., Brunelle-Navas, M. N., Lerner, L. K., et al. (2020). Mitochondrial AIF loss causes metabolic reprogramming, caspase-independent cell death blockade, embryonic lethality, and perinatal hydrocephalus. Mol. Metab. 40:2020. doi: 10.1016/j.molmet.2020.101027

Di Fonzo, A., Ronchi, D., Lodi, T., Fassone, E., Tigano, M., Lamperti, C., et al. (2009). The Mitochondrial Disulfide Relay System Protein GFER Is Mutated in Autosomal-Recessive Myopathy with Cataract and Combined RespiratoryChain Deficiency. Am. J. Hum. Genet. 84, 594-604. doi: 10.1016/j.ajhg.2009. 04.004

Diaz, F., Fukui, H., Garcia, S., and Moraes, C. T. (2006). Cytochrome c Oxidase Is Required for the Assembly/Stability of Respiratory Complex I in Mouse Fibroblasts. Mol. Cell. Biol. 26, 4872-4881. doi: 10.1128/mcb.01767-05

Dickson-Murray, E., Nedara, K., Modjtahedi, N., and Tokatlidis, K. (2021). The mia40/chchd4 oxidative folding system: Redox regulation and signaling in the mitochondrial intermembrane space. Antioxidants 10:10040592. doi: 10.3390/ antiox 10040592

Dimmer, K. S., Papić, D., Schumann, B., Sperl, D., Krumpe, K., Walther, D. M., et al. (2012). A crucial role for Mim2 in the biogenesis of mitochondrial outer membrane proteins. J. Cell Sci. 125, 3464-3473. doi: 10.1242/jcs.103804

Dogan, S. A., Cerutti, R., Benincá, C., Brea-Calvo, G., Jacobs, H. T., Zeviani, M., et al. (2018). Perturbed Redox Signaling Exacerbates a Mitochondrial Myopathy. Cell Metab. 28, 764.e-775.e. doi: 10.1016/j.cmet.2018.07.012 
Fernandez-Vizarra, E., and Zeviani, M. (2021). Mitochondrial disorders of the OXPHOS system. FEBS Lett. 595, 1062-1106. doi: 10.1002/1873-3468.13995

Fischer, M., Horn, S., Belkacemi, A., Kojer, K., Petrungaro, C., Habich, M., et al. (2013). Protein import and oxidative folding in the mitochondrial intermembrane space of intact mammalian cells. Mol. Biol. Cell 24, 2160-2170. doi: 10.1091/mbc.E12-12-0862

Floyd, B. J., Wilkerson, E. M., Veling, M. T., Minogue, C. E., Xia, C., Beebe, E. T., et al. (2016). Mitochondrial Protein Interaction Mapping Identifies Regulators of Respiratory Chain Function. Mol. Cell 63, 621-632. doi: 10.1016/j.molcel. 2016.06.033

Formosa, L. E., Maghool, S., Sharpe, A. J., Reljic, B., Wong, L., Stroud, D. A., et al. (2021). Mitochondrial COA7 is a heme-binding protein involved in the early stages of complex 1 IV assembly. 2 3. bioRxiv 2021:447992. doi: 10.1101/2021. 06.10.447992

Friederich, M. W., Erdogan, A. J., Coughlin, C. R., Elos, M. T., Jiang, H., O’Rourke, C. P., et al. (2017). Mutations in the accessory subunit NDUFB10 result in isolated complex I deficiency and illustrate the critical role of intermembrane space import for complex I holoenzyme assembly. Hum. Mol. Genet. 26, 702-716. doi: $10.1093 / \mathrm{hmg} / \mathrm{ddw} 431$

Gabriel, K., Milenkovic, D., Chacinska, A., Müller, J., Guiard, B., Pfanner, N., et al. (2007). Novel Mitochondrial Intermembrane Space Proteins as Substrates of the MIA Import Pathway. J. Mol. Biol. 365, 612-620. doi: 10.1016/j.jmb.2006. 10.038

Gerashchenko, M. V., Lobanov, A. V., and Gladyshev, V. N. (2012). Genomewide ribosome profiling reveals complex translational regulation in response to oxidative stress. Proc. Natl. Acad. Sci. U. S. A. 109, 17394-17399. doi: 10.1073/ pnas.1120799109

Ghafourifar, P., and Cadenas, E. (2005). Mitochondrial nitric oxide synthase. Trends Pharmacol. Sci. 26, 190-195. doi: 10.1016/j.tips.2005.02.005

Ghezzi, D., Sevrioukova, I., Invernizzi, F., Lamperti, C., Mora, M., D’Adamo, P., et al. (2010). Severe X-Linked Mitochondrial Encephalomyopathy Associated with a Mutation in Apoptosis-Inducing Factor. Am. J. Hum. Genet. 86, 639-649. doi: 10.1016/j.ajhg.2010.03.002

Ghosh, A., Pratt, A. T., Soma, S., Theriault, S. G., Griffin, A. T., Trivedi, P. P., et al. (2016). Mitochondrial disease genes COA6, COX6B and SCO2 have overlapping roles in COX2 biogenesis. Hum. Mol. Genet. 25, 660-671. doi: $10.1093 / \mathrm{hmg} / \mathrm{ddv} 503$

Ghosh, A., Trivedi, P. P., Timbalia, S. A., Griffin, A. T., Rahn, J. J., Chan, S. S. L., et al. (2014). Copper supplementation restores cytochrome $c$ oxidase assembly defect in a mitochondrial disease model of COA6 deficiency. Hum. Mol. Genet. 23, 3596-3606. doi: 10.1093/hmg/ddu069

Gladyck, S., Aras, S., Hüttemann, M., and Grossman, L. I. (2021). Regulation of COX Assembly and Function by Twin CX9C Proteins-Implications for Human Disease. Cells 10:10020197. doi: 10.3390/cells10020197

Grevel, A., Pfanner, N., and Becker, T. (2019). Coupling of import and assembly pathways in mitochondrial protein biogenesis. Biol. Chem. 2019:310. doi: 10. 1515/hsz-2019-0310

Groß, D. P., Burgard, C. A., Reddehase, S., Leitch, J. M., Culotta, V. C., and Hell, K. (2011). Mitochondrial Ccs1 contains a structural disulfide bond crucial for the import of this unconventional substrate by the disulfide relay system. Mol. Biol. Cell 22, 3758-3767. doi: 10.1091/mbc.E11-04-0296

Guarani, V., Paulo, J., Zhai, B., Huttlin, E. L., Gygi, S. P., and Harper, J. W. (2014). TIMMDC1/C3orf1 Functions as a Membrane-Embedded Mitochondrial Complex I Assembly Factor through Association with the MCIA Complex. Mol. Cell. Biol. 34, 847-861. doi: 10.1128/mcb.01551-13

Guarás, A., Perales-Clemente, E., Calvo, E., Acín-Pérez, R., Loureiro-Lopez, M., Pujol, C., et al. (2016). The CoQH2/CoQ Ratio Serves as a Sensor of Respiratory Chain Efficiency. Cell Rep. 15, 197-209. doi: 10.1016/j.celrep.2016.03.009

Guerrero-Castillo, S., Baertling, F., Kownatzki, D., Wessels, H. J., Arnold, S., Brandt, U., et al. (2017). The Assembly Pathway of Mitochondrial Respiratory Chain Complex I. Cell Metab. 25, 128-139. doi: 10.1016/j.cmet.2016.09.002

Guzy, R. D., Hoyos, B., Robin, E., Chen, H., Liu, L., Mansfield, K. D., et al. (2005). Mitochondrial complex III is required for hypoxia-induced ROS production and cellular oxygen sensing. Cell Metab. 1, 401-408. doi: 10.1016/j.cmet.2005. 05.001

Habich, M., Salscheider, S. L., Murschall, L. M., Hoehne, M. N., Fischer, M., Schorn, F., et al. (2019a). Vectorial Import via a Metastable Disulfide-Linked Complex
Allows for a Quality Control Step and Import by the Mitochondrial Disulfide Relay. Cell Rep. 26, 759.e-774.e. doi: 10.1016/j.celrep.2018.12.092

Habich, M., Salscheider, S. L., and Riemer, J. (2019b). Cysteine residues in mitochondrial intermembrane space proteins: more than just import. $\mathrm{Br} . \mathrm{J}$. Pharmacol. 176, 514-531. doi: 10.1111/bph.14480

Han, D., Antunes, F., Canali, R., Rettori, D., and Cadenas, E. (2003). Voltagedependent anion channels control the release of the superoxide anion from mitochondria to cytosol. J. Biol. Chem. 278, 5557-5563. doi: 10.1074/jbc. M210269200

Hangen, E., Féraud, O., Lachkar, S., Mou, H., Doti, N., Fimia, G. M., et al. (2015). Interaction between AIF and CHCHD4 Regulates Respiratory Chain Biogenesis. Mol. Cell 58, 1001-1014. doi: 10.1016/j.molcel.2015.04.020

Hansen, K. G., and Herrmann, J. M. (2019). Transport of Proteins into Mitochondria. Protein J. 2019:6. doi: 10.1007/s10930-019-09819-6

Harner, M., Körner, C., Walther, D., Mokranjac, D., Kaesmacher, J., Welsch, U., et al. (2011). The mitochondrial contact site complex, a determinant of mitochondrial architecture. EMBO J. 30, 4356-4370. doi: 10.1038/emboj. 2011.379

Hartley, A. M., Lukoyanova, N., Zhang, Y., Cabrera-Orefice, A., Arnold, S., Meunier, B., et al. (2019). Structure of yeast cytochrome c oxidase in a supercomplex with cytochrome bc 1. Nat. Struct. Mol. Biol. 26, 78-83. doi: 10.1038/s41594-018-0172-z

Head, B., Griparic, L., Amiri, M., Gandre-Babbe, S., and Van Der Bliek, A. M. (2009). Inducible proteolytic inactivation of OPA1 mediated by the OMA1 protease in mammalian cells. J. Cell Biol. 187, 959-966. doi: 10.1083/jcb. 200906083

Heaton, D., Nittis, T., Srinivasan, C., and Winge, D. R. (2000). Mutational analysis of the mitochondrial copper metallochaperone Cox17. J. Biol. Chem. 275, 37582-37587. doi: 10.1074/jbc.M006639200

Heaton, D. N., George, G. N., Garrison, G., and Winge, D. R. (2001). The mitochondrial copper metallochaperone Cox17 exists as an oligomeric, polycopper complex. Biochemistry 40, 743-751. doi: 10.1021/bi002315x

Helman, G., Compton, A. G., Hock, D. H., Walkiewicz, M., Brett, G. R., Pais, L., et al. (2021). Multiomic analysis elucidates Complex I deficiency caused by a deep intronic variant in NDUFB10. Hum. Mutat. 42, 19-24. doi: 10.1002/humu. 24135

Higuchi, Y., Okunushi, R., Hara, T., Hashiguchi, A., Yuan, J., Yoshimura, A., et al. (2018). Mutations in COA7 cause spinocerebellar ataxia with axonal neuropathy. Brain 141, 1622-1636. doi: 10.1093/brain/awy104

Hirst, J., and Roessler, M. M. (2016). Energy conversion, redox catalysis and generation of reactive oxygen species by respiratory complex $i$. Biochim. Biophys. Acta - Bioenerg. 1857, 872-883. doi: 10.1016/j.bbabio.2015. 12.009

Hiser, L., Di Valentin, M., Hamer, A. G., and Hosler, J. P. (2000). Cox11p is required for stable formation of the $\mathrm{Cu}(\mathrm{B})$ and magnesium centers of cytochrome $\mathrm{c}$ oxidase. J. Biol. Chem. 275, 619-623. doi: 10.1074/jbc.275.1.619

Hofmann, S., Rothbauer, U., Mühlenbein, N., Baiker, K., Hell, K., and Bauer, M. F. (2005). Functional and mutational characterization of human MIA40 acting during import into the mitochondrial intermembrane space. J. Mol. Biol. 353, 517-528. doi: 10.1016/j.jmb.2005.08.064

Holmström, K. M., and Finkel, T. (2014). Cellular mechanisms and physiological consequences of redox-dependent signalling. Nat. Rev. Mol. Cell Biol. 15, 411-421. doi: 10.1038/nrm3801

Horn, D., Al-Ali, H., and Barrientos, A. (2008). Cmclp Is a Conserved Mitochondrial Twin CX 9 C Protein Involved in Cytochrome c Oxidase Biogenesis. Mol. Cell. Biol. 28, 4354-4364. doi: 10.1128/mcb.01920-07

Horn, D., Zhou, W., Trevisson, E., Al-Ali, H., Harris, T. K., Salviati, L., et al. (2010). The conserved mitochondrial twin $\mathrm{Cx} 9 \mathrm{C}$ Protein $\mathrm{Cmc} 2$ is a $\mathrm{Cmc1}$ homologue essential for cytochrome c oxidase biogenesis. J. Biol. Chem. 285, 15088-15099. doi: 10.1074/jbc.M110.104786

Horng, Y. C., Cobine, P. A., Maxfield, A. B., Carr, H. S., and Winge, D. R. (2004). Specific copper transfer from the Cox17 metallochaperone to both Scol and Cox11 in the assembly of yeast cytochrome c oxidase. J. Biol. Chem. 279, 35334-35340. doi: 10.1074/jbc.M404747200

Huigsloot, M., Nijtmans, L. G., Szklarczyk, R., Baars, M. J. H., Van Den Brand, M. A. M., Hendriksfranssen, M. G. M., et al. (2011). A mutation in C2orf64 causes impaired cytochrome $c$ oxidase assembly and mitochondrial 
cardiomyopathy. Am. J. Hum. Genet. 88, 488-493. doi: 10.1016/j.ajhg.2011. 03.002

Hung, V., Zou, P., Rhee, H. W., Udeshi, N. D., Cracan, V., Svinkina, T., et al. (2014). Proteomic Mapping of the Human Mitochondrial Intermembrane Space in Live Cells via Ratiometric APEX Tagging. Mol. Cell 55, 332-341. doi: 10.1016/j. molcel.2014.06.003

Hunte, C., Koepke, J., Lange, C., Roßmanith, T., and Michel, H. (2000). Structure at $2.3 \AA$ resolution of the cytochrome bcl complex from the yeast Saccharomyces cerevisiae co-crystallized with an antibody Fv fragment. Structure 8, 669-684. doi: 10.1016/S0969-2126(00)00152-0

Iñarrea, P., Moini, H., Han, D., Rettori, D., Aguiló, I., Alava, M. A., et al. (2007). Mitochondrial respiratory chain and thioredoxin reductase regulate intermembrane $\mathrm{Cu}, \mathrm{Zn}$-superoxide dismutase activity: Implications for mitochondrial energy metabolism and apoptosis. Biochem. J. 405, 173-179. doi: 10.1042/BJ20061809

Iñarrea, P., Moini, H., Rettori, D., Han, D., Martínez, J., García, I., et al. (2005). Redox activation of mitochondrial intermembrane space $\mathrm{Cu}, \mathrm{Zn}$-superoxide dismutase. Biochem. J. 387, 203-209. doi: 10.1042/BJ20041683

Iwata, S., Lee, J. W., Okada, K., Lee, J. K., Iwata, M., Rasmussen, B., et al. (1998). Complete structure of the 11-subunit bovine mitochondrial cytochrome bc1 complex. Science 281, 64-71. doi: 10.1126/science.281. 5373.64

Jacob, C., Holme, A. L., and Fry, F. H. (2004). The sulfinic acid switch in proteins. Org. Biomol. Chem. 2, 1953-1956. doi: 10.1039/b406180b

Jäer, S., Handschin, C., St-Pierre, J., and Spiegelman, B. M. (2007). AMP-activated protein kinase (AMPK) action in skeletal muscle via direct phosphorylation of PGC-1 $\alpha$. Proc. Natl. Acad. Sci. U. S. A. 104, 12017-12022. doi: 10.1073/pnas. 0705070104

Jaksch, M., Ogilvie, I., Yao, J., Kortenhaus, G., Bresser, H. G., Gerbitz, K. D., et al. (2000). Mutations in SCO2 are associated with a distinct form of hypertrophic cardiomyopathy and cytochrome c oxidase deficiency. Hum. Mol. Genet. 9, 795-801. doi: 10.1093/hmg/9.5.795

Jensen, R. E., and Johnson, A. E. (2001). Opening the door to mitochondrial protein import. Nat. Struct. Biol. 8, 1008-1010. doi: 10.1038/nsb1201-1008

Jett, K. A., and Leary, S. C. (2018). Building the CuA site of cytochrome c oxidase: A complicated, redox-dependent process driven by a surprisingly large complement of accessory proteins. J. Biol. Chem. 293, 4644-4652. doi: 10.1074/ jbc.R117.816132

Ji, L. L., and Yeo, D. (2021). Oxidative stress: an evolving definition. Fac. Rev. 10:13. doi: $10.12703 / \mathrm{r} / 10-13$

Kadenbach, B., and Hüttemann, M. (2015). The subunit composition and function of mammalian cytochrome c oxidase. Mitochondrion 24, 64-76. doi: 10.1016/j. mito.2015.07.002

Kallergi, E., Andreadaki, M., Kritsiligkou, P., Katrakili, N., Pozidis, C., Tokatlidis, K., et al. (2012). Targeting and maturation of Ervl/ALR in the mitochondrial intermembrane space. ACS Chem. Biol. 7, 707-714. doi: 10.1021/cb200485b

Käser, M., Kambacheld, M., Kisters-Woike, B., and Langer, T. (2003). Oma1, a Novel Membrane-bound Metallopeptidase in Mitochondria with Activities Overlapping with the m-AAA Protease. J. Biol. Chem. 278, 46414-46423. doi: 10.1074/jbc.M305584200

Kawano, S., Yamano, K., Naoé, M., Momose, T., Terao, K., Nishikawa, S. I., et al. (2009). Structural basis of yeast Tim40/Mia40 as an oxidative translocator in the mitochondrial intermembrane space. Proc. Natl. Acad. Sci. U. S. A. 106, 14403-14407. doi: 10.1073/pnas.0901793106

Khalimonchuk, O., Bird, A., and Winge, D. R. (2007). Evidence for a pro-oxidant intermediate in the assembly of cytochrome oxidase. J. Biol. Chem. 282, 1744217449. doi: 10.1074/jbc.M702379200

Khalimonchuk, O., Jeong, M. Y., Watts, T., Ferris, E., and Winge, D. R. (2012). Selective Omal protease-mediated proteolysis of Coxl subunit of cytochrome oxidase in assembly mutants. J. Biol. Chem. 287, 7289-7300. doi: 10.1074/jbc. M111.313148

Khalimonchuk, O., Rigby, K., Bestwick, M., Pierrel, F., Cobine, P. A., and Winge, D. R. (2008). Pet191 is a cytochrome c oxidase assembly factor in Saccharomyces cerevisiae. Eukaryot. Cell 7, 1427-1431. doi: 10.1128/EC.00 132-08

Khalimonchuk, O., and Winge, D. R. (2008). Function and redox state of mitochondrial localized cysteine-rich proteins important in the assembly of cytochrome c oxidase. Biochim. Biophys. Acta - Mol. Cell Res. 1783, 618-628. doi: 10.1016/j.bbamcr.2007.10.016

Kimura, Y., Goto, Y. I., and Kimura, H. (2010). Hydrogen sulfide increases glutathione production and suppresses oxidative stress in mitochondria. Antioxidants Redox Signal. 12, 1-13. doi: 10.1089/ars.2008.2282

Klein, A., Israel, L., Lackey, S. W. K., Nargang, F. E., Imhof, A., Baumeister, W., et al. (2012). Characterization of the insertase for $\beta$-barrel proteins of the outer mitochondrial membrane. J. Cell Biol. 199, 599-611. doi: 10.1083/jcb. 201207161

Koch, J. R., and Schmid, F. X. (2014a). Mia40 combines thiol oxidase and disulfide isomerase activity to efficiently catalyze oxidative folding in mitochondria. J. Mol. Biol. 426, 4087-4098. doi: 10.1016/j.jmb.2014.10.022

Koch, J. R., and Schmid, F. X. (2014b). Mia40 targets cysteines in a hydrophobic environment to direct oxidative protein folding in the mitochondria. Nat. Commun. 5:4041. doi: 10.1038/ncomms4041

Koehler, C. M. (2004). The small Tim proteins and the twin Cx3C motif. Trends Biochem. Sci. 29, 1-4. doi: 10.1016/j.tibs.2003.11.003

Kojer, K., Bien, M., Gangel, H., Morgan, B., Dick, T. P., and Riemer, J. (2012). Glutathione redox potential in the mitochondrial intermembrane space is linked to the cytosol and impacts the Mia40 redox state. EMBO J. 31, 3169-3182. doi: 10.1038/emboj.2012.165

Kojer, K., Peleh, V., Calabrese, G., Herrmann, J. M., and Riemer, J. (2015). Kinetic control by limiting glutaredoxin amounts enables thiol oxidation in the reducing mitochondrial intermembrane space. Mol. Biol. Cell 26, 195-204. doi: 10.1091/mbc.E14-10-1422

Kowaltowski, A. J., de Souza-Pinto, N. C., Castilho, R. F., and Vercesi, A. E. (2009). Mitochondria and reactive oxygen species. Free Radic. Biol. Med. 47, 333-343. doi: 10.1016/j.freeradbiomed.2009.05.004

Kozjak-Pavlovic, V., Prell, F., Thiede, B., Götz, M., Wosiek, D., Ott, C., et al. (2014). C1orf163/RESA1 is a novel mitochondrial intermembrane space protein connected to respiratory chain assembly. J. Mol. Biol. 426, 908-920. doi: 10. 1016/j.jmb.2013.12.001

Kritsiligkou, P., Chatzi, A., Charalampous, G., Mironov, A., Grant, C. M., and Tokatlidis, K. (2017). Unconventional Targeting of a Thiol Peroxidase to the Mitochondrial Intermembrane Space Facilitates Oxidative Protein Folding. Cell Rep. 18, 2729-2741. doi: 10.1016/j.celrep.2017.02.053

Kutik, S., Stojanovski, D., Becker, L., Becker, T., Meinecke, M., Krüger, V., et al. (2008). Dissecting Membrane Insertion of Mitochondrial $\beta$-Barrel Proteins. Cell 132, 1011-1024. doi: 10.1016/j.cell.2008.01.028

Lambert, A. J., and Brand, M. D. (2009). Reactive oxygen species production by mitochondria. Methods Mol. Biol. 554, 165-181. doi: 10.1007/978-1-59745521-3_11

Lange, H., Lisowsky, T., Gerber, J., Mühlenhoff, U., Kispal, G., and Lill, R. (2001). An essential function of the mitochondrial sulfhydryl oxidase Erv1p/ALR in the maturation of cytosolic Fe/S proteins. EMBO Rep. 2, 715-720. doi: 10.1093/ embo-reports/kve161

Leary, S. C., Cobine, P. A., Kaufman, B. A., Guercin, G. H., Mattman, A., Palaty, J., et al. (2007). The Human Cytochrome c Oxidase Assembly Factors SCO1 and SCO2 Have Regulatory Roles in the Maintenance of Cellular Copper Homeostasis. Cell Metab. 5, 9-20. doi: 10.1016/j.cmet.2006. 12.001

Leary, S. C., Cobine, P. A., Nishimura, T., Verdijk, R. M., De Krijger, R., De Coo, R., et al. (2013). COX19 mediates the transduction of a mitochondrial redox signal from SCO1 that regulates ATP7A-mediated cellular copper efflux. Mol. Biol. Cell 24, 683-691. doi: 10.1091/mbc.E12-09-0705

Leary, S. C., Kaufman, B. A., Pellecchia, G., Guercin, G. H., Mattman, A., Jaksch, M., et al. (2004). Human SCO1 and SCO2 have independent, cooperative functions in copper delivery to cytochrome c oxidase. Hum. Mol. Genet. 13, 1839-1848. doi: 10.1093/hmg/ddh197

Leary, S. C., Sasarman, F., Nishimura, T., and Shoubridge, E. A. (2009). Human SCO2 is required for the synthesis of CO II and as a thiol-disulphide oxidoreductase for SCO1. Hum. Mol. Genet. 18, 2230-2240. doi: 10.1093/hmg/ ddp 158

Leonhard, K., Guiard, B., Pellecchia, G., Tzagoloff, A., Neupert, W., and Langer, T. (2000). Membrane protein degradation by AAA proteases in mitochondria: Extraction of substrates from either membrane surface. Mol. Cell 5, 629-638. doi: 10.1016/S1097-2765(00)80242-7 
Leonhard, K., Herrmann, J. M., Stuart, R. A., Mannhaupt, G., Neupert, W., and Langer, T. (1996). AAA proteases with catalytic sites on apposite membrane surfaces comprise a proteolytic system for the ATP-dependent degradation of inner membrane proteins in mitochondria. EMBO J. 15, 4218-4229. doi: 10.1002/j.1460-2075.1996.tb00796.x

Leonhard, K., Stiegler, A., Neupert, W., and Langer, T. (1999). Chaperone-like activity of the AAA domain of the yeast Ymel AAA protease. Nature 398, 348-351. doi: 10.1038/18704

Letts, J. A., and Sazanov, L. A. (2017). Clarifying the supercomplex: The higherorder organization of the mitochondrial electron transport chain. Nat. Struct. Mol. Biol. 24, 800-808. doi: 10.1038/nsmb.3460

Liang, H., Yoo, S. E., Na, R., Walter, C. A., Richardson, A., and Ran, Q. (2009). Short form glutathione peroxidase 4 is the essential isoform required for survival and somatic mitochondrial functions. J. Biol. Chem. 284, 30836-30844. doi: 10.1074/jbc.M109.032839

Lionaki, E., Aivaliotis, M., Pozidis, C., and Tokatlidis, K. (2010). The N-terminal shuttle domain of Erv1 determines the affinity for Mia 40 and mediates electron transfer to the catalytic Ervl core in yeast mitochondria. Antioxidants Redox Signal. 13, 1327-1339. doi: 10.1089/ars.2010.3200

Liu, R., and Chan, D. C. (2017). OPA1 and cardiolipin team up for mitochondrial fusion. Nat. Cell Biol. 19, 760-762. doi: 10.1038/ncb3565

Lobo-Jarne, T., and Ugalde, C. (2018). Respiratory chain supercomplexes: Structures, function and biogenesis. Semin. Cell Dev. Biol. 76, 179-190. doi: 10.1016/j.semcdb.2017.07.021

Longen, S., Bien, M., Bihlmaier, K., Kloeppel, C., Kauff, F., Hammermeister, M., et al. (2009). Systematic Analysis of the Twin Cx9C Protein Family. J. Mol. Biol. 393, 356-368. doi: 10.1016/j.jmb.2009.08.041

Lu, H., Allen, S., Wardleworth, L., Savory, P., and Tokatlidis, K. (2004). Functional TIM10 Chaperone Assembly Is Redox-regulated in Vivo. J. Biol. Chem. 279, 18952-18958. doi: 10.1074/jbc.M313045200

Lyons, A. M., Ardissone, A., Reyes, A., Robinson, A. J., Moroni, I., Ghezzi, D., et al. (2016). COA7 (C1orf163/RESA1) mutations associated with mitochondrial leukoencephalopathy and cytochrome c oxidase deficiency. J. Med. Genet. 53, 846-849. doi: 10.1136/jmedgenet-2016-104194

Maghool, S., Ryan, M. T., and Maher, M. J. (2020). What role does coa6 play in cytochrome c oxidase biogenesis: A metallochaperone or thiol oxidoreductase, or both? Int. J. Mol. Sci. 21, 1-13. doi: 10.3390/ijms21196983

Massa, V., Fernandez-Vizarra, E., Alshahwan, S., Bakhsh, E., Goffrini, P., Ferrero, I., et al. (2008). Severe Infantile Encephalomyopathy Caused by a Mutation in COX6B1, a Nucleus-Encoded Subunit of Cytochrome C Oxidase. Am. J. Hum. Genet. 82, 1281-1289. doi: 10.1016/j.ajhg.2008.05.002

Mattie, S., Riemer, J., Wideman, J. G., and McBride, H. M. (2018). A new mitofusin topology places the redox-regulated $\mathrm{C}$ terminus in the mitochondrial intermembrane space. J. Cell Biol. 217, 507-515. doi: 10.1083/jcb.20161 1194

Maxfield, A. B., Heaton, D. N., and Winge, D. R. (2004). Cox17 Is Functional When Tethered to the Mitochondrial Inner Membrane. J. Biol. Chem. 279, 5072-5080. doi: 10.1074/jbc.M311772200

McEwen, J. E., Hong, K. H., Park, S., and Preciado, G. T. (1993). Sequence and chromosomal localization of two PET genes required for cytochrome c oxidase assembly in Saccharomyces cerevisiae. Curr. Genet. 23, 9-14. doi: 10.1007/ BF00336742

Melchionda, L., Haack, T. B., Hardy, S., Abbink, T. E. M., Fernandez-Vizarra, E., Lamantea, E., et al. (2014). Mutations in APOPT1, encoding a mitochondrial protein, cause cavitating leukoencephalopathy with cytochrome $\mathrm{c}$ oxidase deficiency. Am. J. Hum. Genet. 95, 315-325. doi: 10.1016/j.ajhg.2014.08.003

Merkwirth, C., and Langer, T. (2009). Prohibitin function within mitochondria: Essential roles for cell proliferation and cristae morphogenesis. Biochim. Biophys. Acta - Mol. Cell Res. 1793, 27-32. doi: 10.1016/j.bbamcr.2008.05.013

Mesecke, N., Terziyska, N., Kozany, C., Baumann, F., Neupert, W., Hell, K., et al. (2005). A disulfide relay system in the intermembrane space of mitochondria that mediates protein import. Cell 121, 1059-1069. doi: 10.1016/j.cell.2005. 04.011

Milenkovic, D., Gabriel, K., Guiard, B., Schulze-Specking, A., Pfanner, N., and Chacinska, A. (2007). Biogenesis of the essential Tim9-Tim10 chaperone complex of mitochondria: Site-specific recognition of cysteine residues by the intermembrane space receptor Mia40. J. Biol. Chem. 282, 22472-22480. doi: 10.1074/jbc.M703294200
Milenkovic, D., Ramming, T., Müller, J. M., Wenz, L. S., Gebert, N., SchulzeSpecking, A., et al. (2009). Identification of the signal directing Tim 9 and Tim 10 into the intermembrane space of mitochondria. Mol. Biol. Cell 20, 2530-2539. doi: 10.1091/mbc.E08-11-1108

Mohanraj, K., Wasilewski, M., Benincá, C., Cysewski, D., Poznanski, J., Sakowska, P., et al. (2019). Inhibition of proteasome rescues a pathogenic variant of respiratory chain assembly factor COA7. EMBO Mol. Med. 11:201809561. doi: 10.15252/emmm.201809561

Moira Glerum, D., Shtanko, A., and Tzagoloff, A. (1996a). Characterization of COX17, a yeast gene involved in copper metabolism and assembly of cytochrome oxidase. J. Biol. Chem. 271, 14504-14509. doi: 10.1074/jbc.271.24. 14504

Moira Glerum, D., Shtanko, A., and Tzagoloff, A. (1996b). SCO1 and SCO2 act as high copy suppressors of a mitochondrial copper recruitment defect in Saccharomyces cerevisiae. J. Biol. Chem. 271, 20531-20535. doi: 10.1074/jbc. 271.34.20531

Muller, F. L., Liu, Y., and Van Remmen, H. (2004). Complex III releases superoxide to both sides of the inner mitochondrial membrane. J. Biol. Chem. 279, 4906449073. doi: 10.1074/jbc.M407715200

Murari, A., Rhooms, S. K., Goparaju, N. S., Villanueva, M., and OwusuAnsah, E. (2020). An antibody toolbox to track complex I assembly defines AIF's mitochondrial function. J. Cell Biol. 219:202001071. doi: 10.1083/JCB. 202001071

Murphy, M. P. (2009). How mitochondria produce reactive oxygen species. Biochem. J. 417, 1-13. doi: 10.1042/BJ20081386

Murschall, L. M., Gerhards, A., MacVicar, T., Peker, E., Hasberg, L., Wawra, S., et al. (2020). The C-terminal region of the oxidoreductase MIA40 stabilizes its cytosolic precursor during mitochondrial import. BMC Biol. 18:824. doi: 10.1186/s12915-020-00824-1

Naoé, M., Ohwa, Y., Ishikawa, D., Ohshima, C., Nishikawa, S. I., Yamamoto, H., et al. (2004). Identification of Tim 40 that mediates protein sorting to the mitochondrial intermembrane space. J. Biol. Chem. 279, 47815-47821. doi: 10.1074/jbc.M410272200

Neal, S. E., Dabir, D. V., Wijaya, J., Boon, C., and Koehler, C. M. (2017). Osm1 facilitates the transfer of electrons from Ervl to fumarate in the redox-regulated import pathway in the mitochondrial intermembrane space. Mol. Biol. Cell 28, 2773-2785. doi: 10.1091/mbc.E16-10-0712

Nittis, T., George, G. N., and Winge, D. R. (2001). Yeast Sco1, a Protein Essential for Cytochrome c Oxidase Function Is a Cu(I)-binding Protein. J. Biol. Chem. 276, 42520-42526. doi: 10.1074/jbc.M107077200

Nobrega, M. P., Bandeira, S. C. B., Beers, J., and Tzagoloff, A. (2002). Characterization of COX19, a widely distributed gene required for expression of mitochondrial cytochrome oxidase. J. Biol. Chem. 277, 40206-40211. doi: 10.1074/jbc.M207348200

Norton, M., Ng, A. C. H., Baird, S., Dumoulin, A., Shutt, T., Mah, N., et al. (2014). ROMO1 is an essential redox-dependent regulator of mitochondrial dynamics. Sci. Signal. 7:2004374. doi: 10.1126/scisignal.2004374

Osman, C., Wilmes, C., Tatsuta, T., and Langer, T. (2007). Prohibitins interact genetically with Atp23, a novel processing peptidase and chaperone for the F1FO-ATP synthase. Mol. Biol. Cell 18, 627-635. doi: 10.1091/mbc.E06-090839

Oswald, C., Krause-Buchholz, U., and Rödel, G. (2009). Knockdown of Human COX17 Affects Assembly and Supramolecular Organization of Cytochrome c Oxidase. J. Mol. Biol. 389, 470-479. doi: 10.1016/j.jmb.2009. 04.034

Pacheu-Grau, D., Bareth, B., Dudek, J., Juris, L., Vögtle, F. N., Wissel, M., et al. (2015). Cooperation between COA6 and SCO2 in COX2 maturation during cytochrome coxidase assembly links two mitochondrial cardiomyopathies. Cell Metab. 21, 823-833. doi: 10.1016/j.cmet.2015.04.012

Pacheu-Grau, D., Wasilewski, M., Oeljeklaus, S., Gibhardt, C. S., Aich, A., Chudenkova, M., et al. (2020). COA6 Facilitates Cytochrome c Oxidase Biogenesis as Thiol-reductase for Copper Metallochaperones in Mitochondria. J. Mol. Biol. 432, 2067-2079. doi: 10.1016/j.jmb.2020.01.036

Pagliarini, D. J., Calvo, S. E., Chang, B., Sheth, S. A., Vafai, S. B., Ong, S. E., et al. (2008). A Mitochondrial Protein Compendium Elucidates Complex I Disease Biology. Cell 134, 112-123. doi: 10.1016/j.cell.2008.06.016

Pais, J. E., Schilke, B., and Craig, E. A. (2011). Reevaluation of the role of the Pam18:Pam16 interaction in translocation of proteins by the mitochondrial 
Hsp70-based import motor. Mol. Biol. Cell 22, 4740-4749. doi: 10.1091/mbc. E11-08-0715

Páleníková, P., Harbour, M. E., Prodi, F., Minczuk, M., Zeviani, M., Ghelli, A., et al. (2021). Duplexing complexome profiling with SILAC to study human respiratory chain assembly defects. Biochim. Biophys. Acta - Bioenerg. 2021:1862. doi: 10.1016/j.bbabio.2021.148395

Palmeira, C. M., Teodoro, J. S., Amorim, J. A., Steegborn, C., Sinclair, D. A., and Rolo, A. P. (2019). Mitohormesis and metabolic health: The interplay between ROS, cAMP and sirtuins. Free Radic. Biol. Med. 141, 483-491. doi: 10.1016/j. freeradbiomed.2019.07.017

Palumaa, P., Kangur, L., Voronova, A., and Sillard, R. (2004). Metal-binding mechanism of Cox17, a copper chaperone for cytochrome c oxidase. Biochem. J. 382, 307-314. doi: 10.1042/BJ20040360

Papadopoulou, L. C., Sue, M. C., Davidson, M. M., Tanji, K., Nishino, I., Sadlock, J. E., et al. (1999). Fatal infantile cardioencephalomyopathy with COX deficiency and mutations in SCO2, a COX assembly gene. Nat. Genet. 23, 333-337. doi: 10.1038/15513

Paschen, S. A., Waizenegger, T., Stan, T., Preuss, M., Cyrklaff, M., Hell, K., et al. (2003). Evolutionary conservation of biogenesis of $\beta$-barrel membrane proteins. Nature 426, 862-866. doi: 10.1038/nature02208

Paul, B. D., Snyder, S. H., and Kashfi, K. (2021). Effects of hydrogen sulfide on mitochondrial function and cellular bioenergetics. Redox Biol. 38:101772. doi: 10.1016/j.redox.2020.101772

Peker, E., Erdogan, A. J., Volkov, A. N., and Riemer, J. (2021). Erv1 and Cytochrome c Mediate Rapid Electron Transfer via A Collision-Type Interaction. J. Mol. Biol. 433:167045. doi: 10.1016/j.jmb.2021.167045

Peleh, V., Cordat, E., and Herrmann, J. M. (2016). Mia40 is a trans-site receptor that drives protein import into the mitochondrial intermembrane space by hydrophobic substrate binding. Elife 5:16177. doi: 10.7554/eLife. 16177

Petrungaro, C., Zimmermann, K. M., Küttner, V., Fischer, M., Dengjel, J., Bogeski, I., et al. (2015). The Ca2+-dependent release of the Mia40-induced MICU1MICU2 dimer from MCU regulates mitochondrial Ca2+ uptake. Cell Metab. 22, 721-733. doi: 10.1016/j.cmet.2015.08.019

Petruzzella, V., Tiranti, V., Fernandez, P., Ianna, P., Carrozzo, R., and Zeviani, M. (1998). Identification and characterization of human CDNAs specific to BCS1, PET112, SCO1, COX15, and COX11, five genes involved in the formation and function of the mitochondrial respiratory chain. Genomics 54, 494-504. doi: 10.1006/geno.1998.5580

Protasoni, M., Pérez-Pérez, R., Lobo-Jarne, T., Harbour, M. E., Ding, S., Peñas, A., et al. (2020). Respiratory supercomplexes act as a platform for complex III mediated maturation of human mitochondrial complexes I and IV. EMBO J. 39:2019102817. doi: 10.15252/embj.2019102817

Rabinovitch, R. C., Samborska, B., Faubert, B., Ma, E. H., Gravel, S. P., Andrzejewski, S., et al. (2017). AMPK Maintains Cellular Metabolic Homeostasis through Regulation of Mitochondrial Reactive Oxygen Species. Cell Rep. 21, 1-9. doi: 10.1016/j.celrep.2017.09.026

Rainbolt, T. K., Saunders, J. M., and Wiseman, R. L. (2015). YME 1L degradation reduces mitochondrial proteolytic capacity during oxidative stress. EMBO Rep. 16, 97-106. doi: 10.15252/embr.201438976

Rath, S., Sharma, R., Gupta, R., Ast, T., Chan, C., Durham, T. J., et al. (2021). MitoCarta3.0: An updated mitochondrial proteome now with sub-organelle localization and pathway annotations. Nucleic Acids Res. 49, D1541-D1547. doi: 10.1093/nar/gkaa1011

Rathore, S., Berndtsson, J., Marin-Buera, L., Conrad, J., Carroni, M., Brzezinski, P., et al. (2019). Cryo-EM structure of the yeast respiratory supercomplex. Nat. Struct. Mol. Biol. 26, 50-57. doi: 10.1038/s41594-0180169-7

Reczek, C. R., and Chandel, N. S. (2015). ROS-dependent signal transduction. Curr. Opin. Cell Biol. 33, 8-13. doi: 10.1016/j.ceb.2014.09.010

Reinders, J., Zahedi, R. P., Pfanner, N., Meisinger, C., and Sickmann, A. (2006). Toward the complete yeast mitochondrial proteome: Multidimensional separation techniques for mitochondrial proteomics. J. Proteome Res. 5, 15431554. doi: 10.1021/pr050477f

Reinhardt, C., Arena, G., Nedara, K., Edwards, R., Brenner, C., Tokatlidis, K., et al. (2020). AIF meets the CHCHD4/Mia40-dependent mitochondrial import pathway. Biochim. Biophys. Acta - Mol. Basis Dis. 1866:165746. doi: 10.1016/j. bbadis. 2020.165746
Richter, F., Dennerlein, S., Nikolov, M., Jans, D. C., Naumenko, N., Aich, A., et al. (2019). ROMO1 is a constituent of the human presequence translocase required for YME1L protease import. J. Cell Biol. 218, 598-614. doi: 10.1083/ jcb.201806093

Rigby, K., Zhang, L., Cobine, P. A., George, G. N., and Winge, D. R. (2007). Characterization of the cytochrome c oxidase assembly factor Cox19 of Saccharomyces cerevisiae. J. Biol. Chem. 282, 10233-10242. doi: 10.1074/jbc. M610082200

Robb, E. L., Hall, A. R., Prime, T. A., Eaton, S., Szibor, M., Viscomi, C., et al. (2018). Control of mitochondrial superoxide production by reverse electron transport at complex I. J. Biol. Chem. 293, 9869-9879. doi: 10.1074/jbc.RA118.003647

Sakowska, P., Jans, D. C., Mohanraj, K., Riedel, D., Jakobs, S., and Chacinska, A. (2015). The Oxidation Status of Mic19 Regulates MICOS Assembly. Mol. Cell. Biol. 35, 4222-4237. doi: 10.1128/mcb.00578-15

Schendzielorz, A. B., Bragoszewski, P., Naumenko, N., Gomkale, R., Schulz, C., Guiard, B., et al. (2018). Motor recruitment to the TIM23 channel's lateral gate restricts polypeptide release into the inner membrane. Nat. Commun. 9:6492. doi: 10.1038/s41467-018-06492-8

Schreiner, B., Westerburg, H., Forneb, I., Imhof, A., Neupert, W., and Mokranjac, D. (2012). Role of the AAA protease Ymel in folding of proteins in the intermembrane space of mitochondria. Mol. Biol. Cell 23, 4335-4346. doi: 10. 1091/mbc.E12-05-0420

Schulz, T. J., Zarse, K., Voigt, A., Urban, N., Birringer, M., and Ristow, M. (2007). Glucose Restriction Extends Caenorhabditis elegans Life Span by Inducing Mitochondrial Respiration and Increasing Oxidative Stress. Cell Metab. 6, 280-293. doi: 10.1016/j.cmet.2007.08.011

Scialò, F., Fernández-Ayala, D. J., and Sanz, A. (2017). Role of mitochondrial reverse electron transport in ROS signaling: Potential roles in health and disease. Front. Physiol. 8:428. doi: 10.3389/fphys.2017.00428

Scialò, F., Sriram, A., Fernández-Ayala, D., Gubina, N., Lõhmus, M., Nelson, G., et al. (2016). Mitochondrial ROS Produced via Reverse Electron Transport Extend Animal Lifespan. Cell Metab. 23, 725-734. doi: 10.1016/j.cmet.2016. 03.009

Shinzawa-Itoh, K., Sugimura, T., Misaki, T., Tadehara, Y., Yamamoto, S., Hanada, M., et al. (2019). Monomeric structure of an active form of bovine cytochrome c oxidase. Proc. Natl. Acad. Sci. U. S. A. 116, 19945-19951. doi: 10.1073/pnas. 1907183116

Shiota, T., Imai, K., Qiu, J., Hewitt, V. L., Tan, K., Shen, H. H., et al. (2015). Molecular architecture of the active mitochondrial protein gate. Science 349, 1544-1548. doi: 10.1126/science.aac6428

Shutt, T., Geoffrion, M., Milne, R., and McBride, H. M. (2012). The intracellular redox state is a core determinant of mitochondrial fusion. EMBO Rep. 13, 909-915. doi: 10.1038/embor.2012.128

Sickmann, A., Reinders, J., Wagner, Y., Joppich, C., Zahedi, R., Meyer, H. E., et al. (2003). The proteome of Saccharomyces cerevisiae mitochondria. Proc. Natl. Acad. Sci. U. S. A. 100, 13207-13212. doi: 10.1073/pnas.2135385100

Sideris, D. P., Petrakis, N., Katrakili, N., Mikropoulou, D., Gallo, A., Ciofi-Baffoni, S., et al. (2009). A novel intermembrane space-targeting signal docks cysteines onto Mia40 during mitochondrial oxidative folding. J. Cell Biol. 187, 1007-1022. doi: $10.1083 /$ jcb.200905134

Sideris, D. P., and Tokatlidis, K. (2007). Oxidative folding of small Tims is mediated by site-specific docking onto Mia40 in the mitochondrial intermembrane space. Mol. Microbiol. 65, 1360-1373. doi: 10.1111/j.1365-2958. 2007.05880.x

Signes, A., Cerutti, R., Dickson, A. S., Benincá, C., Hinchy, E. C., Ghezzi, D., et al. (2019). APOPT $1 /$ COA 8 assists COX assembly and is oppositely regulated by UPS and ROS. EMBO Mol. Med. 11, 201809582. doi: 10.15252/emmm. 201809582

Signes, A., and Fernandez-Vizarra, E. (2018). Assembly of mammalian oxidative phosphorylation complexes I-V and supercomplexes. Essays Biochem. 62, 255270. doi: 10.1042/EBC20170098

Sinkler, C. A., Kalpage, H., Shay, J., Lee, I., Malek, M. H., Grossman, L. I., et al. (2017). Tissue- and Condition-Specific Isoforms of Mammalian Cytochrome c Oxidase Subunits: From Function to Human Disease. Oxid. Med. Cell. Longev. 2017:153456. doi: 10.1155/2017/1534056

Sirrenberg, C., Bauer, M. F., Guiard, B., Neupert, W., and Brunner, M. (1996). Import of carrier proteins into the mitochondrial inner membrane mediated by Tim22. Nature 384, 582-585. doi: 10.1038/384582a0 
Soma, S., Morgada, M. N., Naik, M. T., Boulet, A., Roesler, A. A., Dziuba, N., et al. (2019). COA6 Is Structurally Tuned to Function as a Thiol-Disulfide Oxidoreductase in Copper Delivery to Mitochondrial Cytochrome c Oxidase. Cell Rep. 29, 4114.e-4126.e. doi: 10.1016/j.celrep.2019.11.054

Stiburek, L., Cesnekova, J., Kostkova, O., Fornuskova, D., Vinsova, K., Wenchich, L., et al. (2012). YME1L controls the accumulation of respiratory chain subunits and is required for apoptotic resistance, cristae morphogenesis, and cell proliferation. Mol. Biol. Cell 23, 1010-1023. doi: 10.1091/mbc.E11-080674

Stroud, D. A., Maher, M. J., Lindau, C., Vögtle, F. N., Frazier, A. E., Surgenor, E., et al. (2015). COA6 is a mitochondrial complex IV assembly factor critical for biogenesis of mtDNA-encoded COX2. Hum. Mol. Genet. 24, 5404-5415. doi: $10.1093 / \mathrm{hmg} / \mathrm{ddv} 265$

Stroud, D. A., Surgenor, E. E., Formosa, L. E., Reljic, B., Frazier, A. E., Dibley, M. G., et al. (2016). Accessory subunits are integral for assembly and function of human mitochondrial complex i. Nature 538, 123-126. doi: 10.1038/ nature 19754

Susin, S. A., Lorenzo, H. K., Zamzami, N., Marzo, I., Snow, B. E., Brothers, G. M., et al. (1999). Molecular characterization of mitochodrial apoptosis-inducing factor. Nature 397, 441-446. doi: 10.1038/17135

Suzuki, Y., Ali, M., Fischer, M., and Riemer, J. (2013). Human copper chaperone for superoxide dismutase 1 mediates its own oxidation-dependent import into mitochondria. Nat. Commun. 4:3430. doi: 10.1038/ncomms3430

Szczepanowska, K., Senft, K., Heidler, J., Herholz, M., Kukat, A., Höhne, M. N., et al. (2020). A salvage pathway maintains highly functional respiratory complex I. Nat. Commun. 11:15567. doi: 10.1038/s41467-020-15467-7

Szczepanowska, K., and Trifunovic, A. (2021). Tune instead of destroy: How proteolysis keeps OXPHOS in shape. Biochim. Biophys. Acta - Bioenerg. 1862:18365. doi: 10.1016/j.bbabio.2020.148365

Szibor, M., Gainutdinov, T., Fernandez-Vizarra, E., Dufour, E., Gizatullina, Z., Debska-Vielhaber, G., et al. (2020). Bioenergetic consequences from xenotopic expression of a tunicate AOX in mouse mitochondria: Switch from RET and ROS to FET. Biochim. Biophys. Acta - Bioenerg. 1861:148137. doi: 10.1016/j. bbabio.2019.148137

Szklarczyk, D., Franceschini, A., Kuhn, M., Simonovic, M., Roth, A., Minguez, P., et al. (2011). The STRING database in 2011: Functional interaction networks of proteins, globally integrated and scored. Nucleic Acids Res. 39:973. doi: 10.1093/ nar/gkq973

Szklarczyk, R., Wanschers, B. F. J., Cuypers, T. D., Esseling, J. J., Riemersma, M., Van Den Brand, M. A. M., et al. (2012). Iterative orthology prediction uncovers new mitochondrial proteins and identifies C12orf62 as the human ortholog of COX14, a protein involved in the assembly of cytochrome c oxidase. Genome Biol. 13:12. doi: 10.1186/gb-2012-13-2-r12

Szklarczyk, R., Wanschers, B. F. J., Nabuurs, S. B., Nouws, J., Nijtmans, L. G., and Huynen, M. A. (2011). NDUFB7 and NDUFA8 are located at the intermembrane surface of complex i. FEBS Lett. 585, 737-743. doi: 10.1016/j. febslet.2011.01.046

Tadokoro, T., Ikeda, M., Ide, T., Deguchi, H., Ikeda, S., Okabe, K., et al. (2020). Mitochondria-dependent ferroptosis plays a pivotal role in doxorubicin cardiotoxicity. JCI Insight 5:132747. doi: 10.1172/jci.insight.132747

Takahashi, Y., Kako, K., Kashiwabara, S., Takehara, A., Inada, Y., Arai, H., et al. (2002). Mammalian Copper Chaperone Cox17p Has an Essential Role in Activation of Cytochrome c Oxidase and Embryonic Development. Mol. Cell. Biol. 22, 7614-7621. doi: 10.1128/mcb.22.21.7614-7621.2002

Takeda, H., Tsutsumi, A., Nishizawa, T., Lindau, C., Busto, J. V., Wenz, L. S., et al. (2021). Mitochondrial sorting and assembly machinery operates by $\beta$-barrel switching. Nature 590, 163-169. doi: 10.1038/s41586-02003113-7

Terziyska, N., Grumbt, B., Bien, M., Neupert, W., Herrmann, J. M., and Hell, K. (2007). The sulfhydryl oxidase Erv1 is a substrate of the Mia40-dependent protein translocation pathway. FEBS Lett. 581, 1098-1102. doi: 10.1016/j. febslet.2007.02.014

Terziyska, N., Lutz, T., Kozany, C., Mokranjac, D., Mesecke, N., Neupert, W., et al. (2005). Mia40, a novel factor for protein import into the intermembrane space of mitochondria is able to bind metal ions. FEBS Lett. 579, 179-184. doi: 10.1016/j.febslet.2004.11.072

Timón-Gómez, A., Nývltová, E., Abriata, L. A., Vila, A. J., Hosler, J., and Barrientos, A. (2018). Mitochondrial cytochrome c oxidase biogenesis: Recent developments. Semin. Cell Dev. Biol. 76, 163-178. doi: 10.1016/j.semcdb.2017. 08.055

Tort, F., Barredo, E., Parthasarathy, R., Ugarteburu, O., Ferrer-Cortès, X., GarcíaVilloria, J., et al. (2020). Biallelic mutations in NDUFA8 cause complex I deficiency in two siblings with favorable clinical evolution. Mol. Genet. Metab. 131, 349-357. doi: 10.1016/j.ymgme.2020.10.005

Tropeano, C. V., Aleo, S. J., Zanna, C., Roberti, M., Scandiffio, L., Loguercio Polosa, P., et al. (2020). Fine-tuning of the respiratory complexes stability and supercomplexes assembly in cells defective of complex III. Biochim. Biophys. Acta-Bioenerg. 1861:148133. doi: 10.1016/j.bbabio.2019.148133

Tsukihara, T., Aoyama, H., Yamashita, E., Tomizaki, T., Yamaguchi, H., ShinzawaItoh, K., et al. (1996). The whole structure of the 13-subunit oxidized cytochrome c oxidase at 2.8 Å. Science 272, 1136-1144. doi: 10.1126/science. 272.5265 .1136

Tzagoloff, A., Capitanio, N., Nobrega, M. P., and Gatti, D. (1990). Cytochrome oxidase assembly in yeast requires the product of COX11, a homolog of the P. denitrificans protein encoded by ORF3. EMBO J. 9, 2759-2764. doi: 10.1002/ j.1460-2075.1990.tb07463.x

Tzagoloff, A., Nobrega, M., Gorman, N., and Sinclair, P. (1993). On the functions of the yeast COX10 and COX11 gene products. Biochem. Mol. Biol. Int. 31, 593-598.

Vahsen, N., Candé, C., Brière, J. J., Bénit, P., Joza, N., Larochette, N., et al. (2004). AIF deficiency compromises oxidative phosphorylation. EMBO J. 23, 4679-4689. doi: 10.1038/sj.emboj.7600461

Valnot, I., Osmond, S., Gigarel, N., Mehaye, B., Amiel, J., Cormier-Daire, V., et al. (2000). Mutations of the SCO1 Gene in Mitochondrial Cytochrome c Oxidase Deficiency with Neonatal-Onset Hepatic Failure and Encephalopathy. Am. J. Hum. Genet. 67, 1104-1109. doi: 10.1016/s0002-9297(07)62940-1

Van Wilpe, S., Ryan, M. T., Hill, K., Maarse, A. C., Meisinger, C., Brix, J., et al. (1999). Tom 22 is a multifunctional organizer of the mitochondrial preprotein translocase. Nature 401, 485-489. doi: 10.1038/46802

Vanišová, M., Burská, D., Křížová, J., Daňhelovská, T., and Zeman, J. (2019). Stable COX17 downregulation leads to alterations in mitochondrial ultrastructure, decreased copper content and impaired cytochrome c oxidase biogenesis in HEK293 cells. Folia Biol. 65, 181-187.

Velázquez, I., and Pardo, J. P. (2001). Kinetic characterization of the rotenoneinsensitive internal NADH: Ubiquinone oxidoreductase of mitochondria from Saccharomyces cerevisiae. Arch. Biochem. Biophys. 389, 7-14. doi: 10.1006/abbi. 2001.2293

Veniamin, S., Sawatzky, L. G., Banting, G. S., and Glerum, D. M. (2011). Characterization of the peroxide sensitivity of COX-deficient yeast strains reveals unexpected relationships between COX assembly proteins. Free Radic. Biol. Med. 51, 1589-1600. doi: 10.1016/j.freeradbiomed.2011.06.024

Verkaart, S., Koopman, W. J. H., van Emst-de Vries, S. E., Nijtmans, L. G. J., van den Heuvel, L. W. P. J., Smeitink, J. A. M., et al. (2007). Superoxide production is inversely related to complex I activity in inherited complex I deficiency. Biochim. Biophys. Acta - Mol. Basis Dis. 1772, 373-381. doi: 10.1016/j.bbadis. 2006.12.009

Vidoni, S., Harbour, M. E., Guerrero-Castillo, S., Signes, A., Ding, S., Fearnley, I. M., et al. (2017). MR-1S Interacts with PET100 and PET117 in ModuleBased Assembly of Human Cytochrome c Oxidase. Cell Rep. 18, 1727-1738. doi: 10.1016/j.celrep.2017.01.044

Vögtle, F. N., Burkhart, J. M., Rao, S., Gerbeth, C., Hinrichs, J., Martinou, J. C., et al. (2012). Intermembrane space proteome of yeast mitochondria. Mol. Cell. Proteomics 11, 1840-1852. doi: 10.1074/mcp.M112.021105

Vögtle, F. N., Wortelkamp, S., Zahedi, R. P., Becker, D., Leidhold, C., Gevaert, K., et al. (2009). Global Analysis of the Mitochondrial N-Proteome Identifies a Processing Peptidase Critical for Protein Stability. Cell 139, 428-439. doi: 10.1016/j.cell.2009.07.045

Wang, T., Liu, H., Itoh, K., Oh, S., Zhao, L., Murata, D., et al. (2021). C9orf72 regulates energy homeostasis by stabilizing mitochondrial complex I assembly. Cell Metab. 33, 531.e-546.e. doi: 10.1016/j.cmet.2021.01.005

Webb, C. T., Gorman, M. A., Lazarou, M., Ryan, M. T., and Gulbis, J. M. (2006). Crystal structure of the mitochondrial chaperone TIM9•10 reveals a six-bladed $\alpha$-propeller. Mol. Cell 21, 123-133. doi: 10.1016/j.molcel.2005.11.010

Weckbecker, D., Longen, S., Riemer, J., and Herrmann, J. M. (2012). Atp23 biogenesis reveals a chaperone-like folding activity of Mia40 in the IMS of mitochondria. EMBO J. 31, 4348-4358. doi: 10.1038/emboj.2012.263 
Weinhäupl, K., Lindau, C., Hessel, A., Wang, Y., Schütze, C., Jores, T., et al. (2018). Structural Basis of Membrane Protein Chaperoning through the Mitochondrial Intermembrane Space. Cell 175, 1365.e-1379.e. doi: 10.1016/j.cell.2018.10.039

Wenz, L. S., Ellenrieder, L., Qiu, J., Bohnert, M., Zufall, N., van der Laan, M., et al. (2015). Sam37 is crucial for formation of the mitochondrial TOMSAM supercomplex, thereby promoting B-barrel biogenesis. J. Cell Biol. 210, 1047-1054. doi: $10.1083 /$ jcb. 201504119

Wikström, M., Krab, K., and Sharma, V. (2018). Oxygen Activation and Energy Conservation by Cytochrome c Oxidase. Chem. Rev. 118, 2469-2490. doi: 10. 1021/acs.chemrev.7b00664

Wikström, M., Sharma, V., Kaila, V. R. I., Hosler, J. P., and Hummer, G. (2015), New perspectives on proton pumping in cellular respiration. Chem. Rev. 115, 2196-2221. doi: 10.1021/cr500448t

Yamamoto, H., Fukui, K., Takahashi, H., Kitamura, S., Shiota, T., Terao, K., et al. (2009). Roles of Tom70 in import of presequence-containing mitochondrial proteins. J. Biol. Chem. 284, 31635-31646. doi: 10.1074/jbc.M109.041756

Yamano, K., Yatsukawa, Y. I., Esaki, M., Aiken Hobbs, A. E., Jensen, R. E., and Endo, T. (2008). Tom 20 and Tom 22 share the common signal recognition pathway in mitochondrial protein import. J. Biol. Chem. 283, 3799-3807. doi: 10.1074/jbc.M708339200

Yang, M., Geli, V., Oppliger, W., Suda, K., James, P., and Schatz, G. (1991). The MAS-encoded processing protease of yeast mitochondria: interaction of the purified enzyme with signal peptides and a purified precursor protein. J. Biol. Chem. 266, 6416-6423. doi: 10.1016/s0021-9258(18)38134-1

Yang, M., and Trumpowers, B. L. (1994). Deletion of QCR6, the gene encoding subunit six of the mitochondrial cytochrome bcl complex, blocks maturation of cytochrome $\mathrm{cl}$, and causes temperature-sensitive petite growth in Saccharomyces cerevisiae. J. Biol. Chem. 269, 1270-1275. doi: 10.1016/s00219258(17)42253-8

Yatsuka, Y., Kishita, Y., Formosa, L. E., Shimura, M., Nozaki, F., Fujii, T., et al. (2020). A homozygous variant in NDUFA8 is associated with developmental delay, microcephaly, and epilepsy due to mitochondrial complex I deficiency. Clin. Genet. 98, 155-165. doi: 10.1111/cge.13773
Zara, V., Conte, L., and Trumpower, B. L. (2009). Biogenesis of the yeast cytochrome bcl complex. Biochim. Biophys. Acta - Mol. Cell Res. 1793, 89-96. doi: 10.1016/j.bbamcr.2008.04.011

Zhu, J., Vinothkumar, K. R., and Hirst, J. (2016). Structure of mammalian respiratory complex i. Nature 536, 354-358. doi: 10.1038/nature19095

Zhu, Z., Yao, J., Johns, T., Fu, K., De Bie, I., Macmillan, C., et al. (1998). SURF1, encoding a factor involved in the biogenesis of cytochrome coxidase, is mutated in Leigh syndrome. Nat. Genet. 20, 337-343. doi: 10.1038/3804

Zhuang, J., Wang, P. Y., Huang, X., Chen, X., Kang, J. G., and Hwang, P. M. (2013). Mitochondrial disulfide relay mediates translocation of p53 and partitions its subcellular activity. Proc. Natl. Acad. Sci. U. S. A. 110, 17356-17361. doi: 10. 1073/pnas.1310908110

Zöller, E., Laborenz, J., Krämer, L., Boos, F., Räschle, M., Todd Alexander, R., et al. (2020). The intermembrane space protein Mix23 is a novel stress-induced mitochondrial import factor. J. Biol. Chem. 295, 14686-14697. doi: 10.1074/jbc. RA120.014247

Conflict of Interest: The authors declare that the research was conducted in the absence of any commercial or financial relationships that could be construed as a potential conflict of interest.

Publisher's Note: All claims expressed in this article are solely those of the authors and do not necessarily represent those of their affiliated organizations, or those of the publisher, the editors and the reviewers. Any product that may be evaluated in this article, or claim that may be made by its manufacturer, is not guaranteed or endorsed by the publisher.

Copyright $\odot 2021$ Geldon, Fernández-Vizarra and Tokatlidis. This is an open-access article distributed under the terms of the Creative Commons Attribution License (CC BY). The use, distribution or reproduction in other forums is permitted, provided the original author(s) and the copyright owner(s) are credited and that the original publication in this journal is cited, in accordance with accepted academic practice. No use, distribution or reproduction is permitted which does not comply with these terms. 